Linköping University in A rts and Science N o. 610

Studies in Language and Culture N 0.24

\title{
Learnables in Action
}

The E mbodied A chievement of Opportunities for Teaching and L earning in Swedish as a Second L anguage Classrooms

A li R eza M ajlesi

\section{Linköping University}

Department of Culture and Communication, Division of L anguage and Culture

Faculty of A rts and Science

Linköping U niversity, SE-581 83 Linköping, Sweden

Linköping 2014 
(c) Ali Reza M ajlesi, 2014

On the cover: Dialogue

Designed by Homa Teimouri Sarkoukolaei

Email: artfilmmana@gmail.com

All rights reserved

Printed in Sweden, Linköping by Linköping U niversity Press, 2014

ISSN 0282-9800

ISB N 978-91-7519-387-8 


\section{Learnables in Action}

The Embodied A chievement of Opportunities for Teaching and L earning in Swedish as a Second L anguage Classrooms

by

A li Reza M ajlesi

M arch 2014

ISB N 978-91-7519-387-8

Linköping University in A rts and Science N o. 610

Studies in L anguage and Culture N o. 24

ISSN 0282-9800 

To my teachers, supervisors, and mentors in Rasht, Tehran, Linköping, Uppsala, Gothenburg, Aarhus, Aalborg, Odense, and Los Angeles with appreciation and admiration.

To my late parents, to my brothers and their families, and especially to my wife with love. 



\begin{abstract}
This doctoral dissertation is an empirical qualitative research study on the emergence of learnables in classrooms of Swedish as a second language. It adopts a dialogical and praxeological approach, and analysis is based on video recorded teacher-student interactivities in classrooms. Learnables are taken to be linguistic items or constructs that are displayed as unknown by students, or problematized by students or teachers, and therefore oriented to as explainable, remediable, or improvable. Learnables are introduced in planned or less planned classroom activities, either in passing, while continuing the current main activity, or in side-sequences. In these activities, teachers and students not only talk, but also use other embodied resources (e.g. pointing) or available artifacts (e.g. worksheets) to highlight linguistic learnables. Teachers and students use these resources for achieving and maintaining intersubjectivity as well as contributing learnables to the interactivities. Through manifest embodied practices, abstract linguistic learnables become objectified, and knowledge about them gets organized in and through joint co-operative activities.
\end{abstract}

Keywords: Learnables, Ethnomethodology, Conversation A nalysis, Dialogism, Second language learning, Multimodal interaction analysis, Gestures, Embodied actions, Classroom discourse, Swedish as a second language

Department of Culture and Communication

Linköping U niversity

SE-581 83 Linköping, Sweden 


\section{Table of Contents}

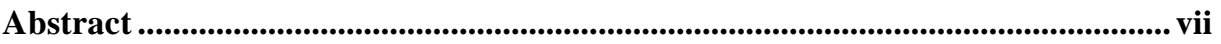

Acknowledgements ................................................................................................................................ $\mathrm{x}$

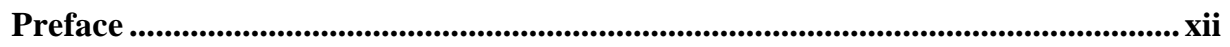

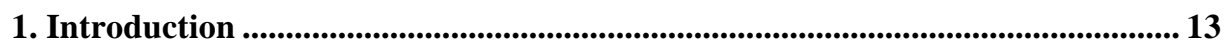

1.1. Aims and research questions ............................................................................... 16

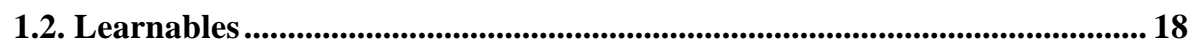

1.3. Outline of the dissertation ................................................................................ 20

2. Approaches to language learning........................................................................21

2.1. The social turn in language learning research: A historical account ......... 21

2.1.1. Learning as a social practice................................................... 22

2.1.2. Interactivities: A $n$ area for language learning research ......................... 26

2.2. EM/CA and language learning activities...............................................28

2.3. The body, talk and the material world in pedagogical activities ................ 31

2.4. A detailed study of interactivities in classroom discourse ........................... 37

2.5. Research on Swedish-for-Immigrants (SFI) classes .................................. 42

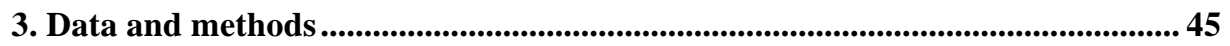

3.1. Swedish-for-Immigrants (SFI) .......................................................................... 45

3.2. The empirical data................................................................................ 47

3.2.1. M ultimodality and video-recording .............................................. 48

3.2.2. Video-recordings; prospects and consequences ................................. 49

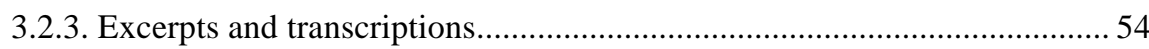

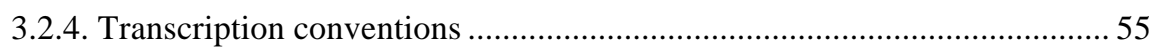

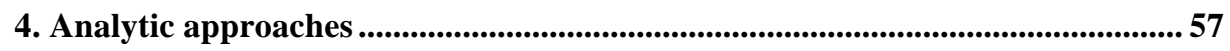

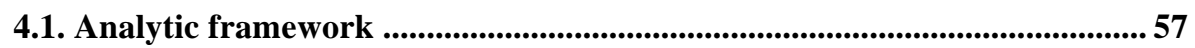

4.2. Praxeology of interactivities as dialogic events.........................................58

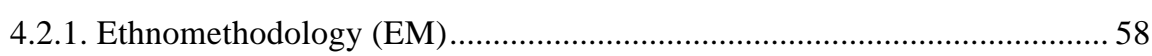

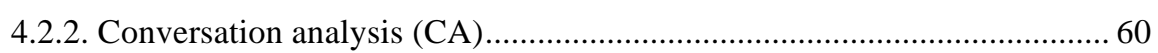




\subsubsection{Notes on some principal concepts in dialogical and praxeological}

methodology

5. Summary of the studies.................................................................................................66

5.1. Study 1: Emergent learnables in second language classroom interaction . 66 5.2. Study 2: Finger dialogue. The embodied accomplishment of learnables in instructing grammar on a worksheet

5.3. Study 3: Matching gestures - Teachers' repetitions of the students' gestures in second language learning classrooms 68

5.4. Study 4: The intersubjective objectivity of learnables - Theoretical underpinnings of praxeological and dialogical research on opportunities for learning in teacher-student interactivities

6. Concluding discussion 72

6.1. The local accomplishment of instructing/learning projects, their theoretical consequences and practical implications..................................................................... 74

6.1.1. Theoretical consequences .............................................................. 75

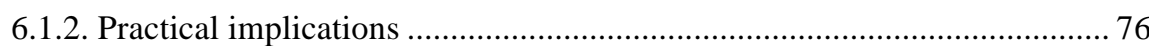

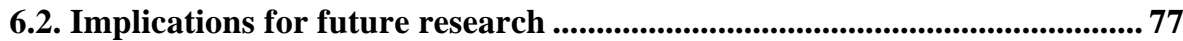

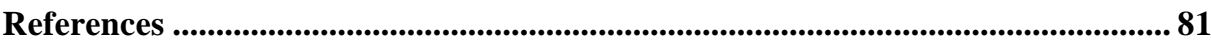

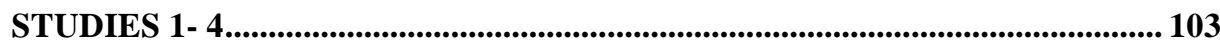




\section{Acknowledgements}

In writing this doctoral dissertation, I am grateful to many people, first and foremost my supervisors for their academic guidance, my colleagues for sharing their experience and expertise with me, and my teachers for the training that I received from them for many years. I extend my sincere gratitude to my supervisors M athias B roth, Per Linell and Charlotta Plejert for their most insightful advice and critiques during the conduct of this research project. I am indebted to the whole Research School of Language and Culture in Europe, to the then dean of the school J an Anward, to the present dean Carin Franzén, and to director of studies Eva Carlestål for their invaluable support and encouragement. I am wholeheartedly thankful to A sta Cekaite, Oskar Lindwall and Charles Goodwin for being external readers of my texts, and for their critiques and comments at different periods of conducting this research.

I am grateful to my hosts at CLIC at UCLA, to Elinor Ochs and especially to Charles Goodwin and Marjorie Goodwin for one of the most fruitful periods of my training. I thank my teachers during my PhD education, those in whose schools of thought I have been trained and have received research skills: Per Linell, Charles Goodwin, Lorenza Mondada, Mathias Broth and Charlotta Plejert. Besides my supervisors who have been by my side working closely with me during the last five years, I spent hours discussing my data with Lorenza M ondada, and A ngelika Linke on many occasions during the time they spent in Linköping. I also benefited a lot from the rewarding courses with Charles Goodwin when I studied at UCLA. I am most sincerely thankful to them. I am appreciative to Paul M cllvenny, Dennis Day, Curtis LeBaron, Birte A smuß, A nna Lindström, M ats Ekström, Srikant Sarangi, Elizabeth Ellsworth, A nssi Peräkylä, J an A nward, A ngelika Linke, Nigel M usk, Simona Pekarek Doehler, John Hellermann, Søren Eskildsen, and Johannes Wagner to whom I owe a lot for my scientific training in their courses and workshops. I also extend my appreciation to those who broadened the horizon of my knowledge in human sciences during my Master's studies and also during the conduct of this doctoral research: Y ahya Modarresi, Mohammad Dabir Moghaddam, Mostafa Asi, Ali Mohammad Haghshenas, Y adollah Samareh, Mohsen Abolghasemi, Shahin Nematzadeh, Iran Kalbasi, Zohreh Zarshenas, Ann-Sofie Persson, Rickard Karlsson, Per Simfors, Victoria Thörnryd, M echtild Tronnier, Richard Hirsch, Eva Carlestål, Jan Paul Strid, L ars-Håkan Svensson, J an Willner, Rikard Roitto, and Frank B aasner. 
Part of my education and training, I definitely owe to the regular data sessions that are in effect at Linköping U niversity run by $A$ sta Cekaite, J akob C romdal and $M$ athias B roth and now managed by Leelo K eevallik as well. It has been a rewarding gathering for the exchange of scientific opinions, and receiving training skills. I should also thank the researchers who were involved in the data sessions both on CLIC occasions for conversation analytic data sessions and at the anthropology department at UCLA. I thank John Heritage, Emanuel Schegloff, Tanya Stivers, Marjorie Goodwin, A lessandro Duranti, Elinor $O$ chs and many more.

During the PhD education, certain people are always resourceful and helpful, especially in the time of need. I would like to show my appreciation to my colleagues in different working places, specifically at the Department of Culture and Communication and the Research School of Language and Culture in Europe at Linköping University, from the dean to the administrators, also to my PhD peers, and to my colleagues, past and present.

I would also like to show my gratitude to the anonymous reviewers who peer reviewed two of the studies included in this dissertation. I am thankful to the examination committee of this doctoral dissertation. I also thank those who, besides my supervisors, helped me to save the dissertation from many shortcomings in writing, in its organization, in its design, and also publication, particularly Norman Davies for offering his professional expertise in a tight time-schedule before the publication.

Finally, and above all, the doctoral dissertation in your hands would never be finished if it were not for the help, support and love that I received from friends and family. I owe this to my family, especially to my wife Fariba who made the most stressful times of writing this dissertation easy to handle with the comfort at home. This journey could not be smoothly brought to an end if my family were not there for me. I finish these acknowledgements by sending my love and appreciation to them.

Linköping, February 2014

Ali Reza M ajlesi 


\section{Preface}

In the preface to his book, The Presentation of Self in Everyday Life, Erving Goffman (1956) described his own analytic observational work as resulting in a 'qualified generalization' in which a set of descriptive features that his work provides for the studied social situations may be applied to any similar settings. Engaged in a distinct undertaking, this research project, too, is a qualitative study of social situations, albeit in a particular setting: Swedish as a Second Language Learning Classrooms. The research project consists of individual studies compiled as a doctoral dissertation. The studies focus on practices that are recursively used for accomplishing learnables in various classroom situations. These practices can be found el sew here too.

However amenable to some generalizations, this research project does not claim, or is not based on, any generic universal models or representational theories. It rather analytically describes (Sacks, 1963) some mundane common-sense practices that participants employ to accomplish particular actions or activities. To do so, participants' practices in classroom interactivities and their observable and reportable methods of accomplishing them (Garfinkel, 1967, 2002) are described in detail as they actually unfold in the circumstance of their occurrences.

The empirical data used for this study is from Swedish-for-Immigrants classes (SFI). SFI is designed especially for non-Swedes to learn Swedish as a second language. When I started the research project, I myself was also one of the participants in SFI and during the span of one and half years, I collected data as a participantobserver. Even though the presented data in this dissertation does not represent SFI as an institution, the interactivities that are analyzed here instantiate the complex social organization of its setting. With this research, what I hope to demonstrate is the interactional work done through the close cooperation of the participants (teachers as well as students) to create opportunities for teaching and learning. W hat is oriented to as a learnable, as demonstrated in this research project, is an achievable social phenomenon. Through focusing on embodied actions in pedagogy, I present some aspects of social construction of this multifaceted environment, which is constituted of many social and cognitive layers and dimensions. 


\section{Introduction}

This research project is an empirical qualitative study on interactivities ${ }^{1}$ in Swedish for immigrants (SFI) (Swedish as a second language). The aim is to show some procedural activities in accomplishing teachable moments (Alibali, Flevares \& Goldin-M eadow, 1997) and learning opportunities. I propose to analyze these learning and teaching projects and opportunities in terms of learnables (M ajlesi \& B roth, 2012; M ajlesi, 2014; Zemel \& K oschmann, 2014). By learnable, I mean a 'thing' or a 'phenomenon', in this case pertaining to language (i.e. Swedish as a second language) that in a social activity, in certain situations is manifestly oriented to, and highlighted (C. Goodwin, 1994) as a new way of telling, seeing, exhibiting, doing, understanding, etc. In language learning situations, a learnable is displayed and treated, practically as a competent way of telling and exhibiting the mastery of that language ( $c f$. Garfinkel \& Sacks, 1986/1970). The activities focused on in this study are episodes of either formal teaching or unplanned conversational sequences. These activities are seen, by analysts and participants alike, as account-able actions. This study is about these actions when used for accomplishing learnables.

With regard to language learning classroom activities, this study offers some suggestive examples of sequences showing how the co-operative organization of different sequence types, with their variable resources elaborating each other ( $c f$. Goodwin, 2013), are exploited in the procedure of accomplishing learnables. It will also be demonstrated that the learnability of the focused phenomenon is not an inherent property but is something made relevant, offered and only treated as such within that activity.

In language learning classrooms, learnables appear not only in correction sequences, grammar, or word search and explanation sequences, but also in non-

\footnotetext{
${ }^{1}$ By interactivity here, I simply mean the activity that is carried out in and through interpersonal interaction between different parties.
} 
pedagogic activities (story telling, non-institutional conversations, etc.), which may be turned into pedagogical opportunities for teaching and learning.

The illustrative example below (Ex.1) may help clarify what this research project deals with. In a Swedish as a second language class, after finishing a group work session, a student (Sandra) leaves her group to go back to her seat in the back row. She goes past another student (Linda) who is almost blocking her way (fig.1). Even though Linda gives way to Sandra on her way past, Sandra gently taps Linda's thigh and her lower back. This prompts Linda to make a Swedish utterance to excuse herself for having a big backside.

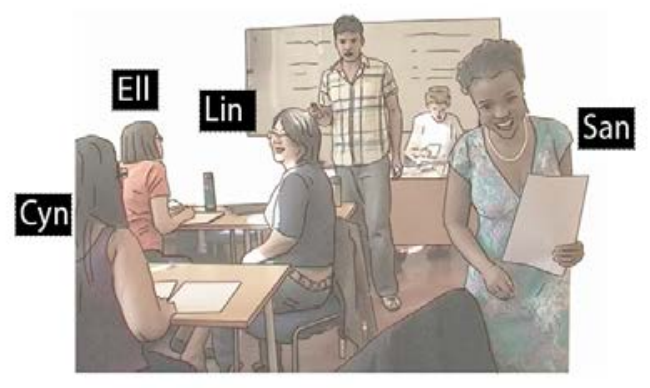

Fig. 1 Linda begins a word search after Sandra's tapping on her lower back.

A n attempt to make an utterance in Swedish turns into a local learning project ( $c f$. communicative projects, see Linell, 1998, 2009; see Study 2) in which a word for 'backside' in Swedish is searched for by Linda, and is visibly and hearably treated as a learnable. This word search sequence (see Goodwin \& Goodwin, 1986) provides not only a language learning opportunity (Brouwer, 2003), but also a demonstration of handling a socially and culturally loaded indexical expression.

In the transcripts, I use illustrative pictures. When the pictures align with the verbal acts, I use dotted brackets and also hashtags (\#) to show where they happen. Otherwise, I explain some significant nonverbal acts in the double parentheses (the list of transcription conventions are presented in the A ppendix). 
Excerpt 1: Big butt: Tape M, C level (Simplified)

Participants: Linda (Lin), Sandra (San), Cynthia (Cyn), and Ellen (EII)

((Sandra taps on Linda's lower back while going past her))

Fig. 2

01 Lin: tyvärr, och (.) jag har (0.1) jätte: (0.2) \#((hits her lower back for four times))

Unfortunately, (.) and I have (0.1) big: (0.2)

02

03 Lin:
(0.8) ((Linda, Sandra and Cynthia laugh)) how can I say? .hh (.) \# big: (.) jätte: HH[hh

big: ((hitting her lower back, turning to Cyn and EII))

04 Ell: he $i$

$05 \quad(0.5)$

06 Lin: I have a big butt. ((hitting her lower back again)) ${ }^{\circ}$ butt. ${ }^{\circ}$

07 Ell: $\quad$ e : (.) ${ }^{\circ}$ skinka $^{\circ} i=$

08 Cyn: =HIHIhi rumpai

$=$ HIHIhi backside:

09 (0.7) ((Linda, Cynthia, Ellen and Sandra laugh together))

10 Ell: e-e- e- STORA, (.) STORA RUMPA.=

e-e- e- BIG, (.) BIG BACKSIDE.=

${ }^{\circ} \mathrm{ja}$ har $($.$) ja har st- HEHEHEHE$
$\%$ have(.) $)$ have bi-

12 Lin: =HEhehehehehe

13 Cyn: aha (0.2) stora stora rumpan HEHEHEhehehehehe big big backside HEHEHEhehehehehehe

This example shows how a commonplace event of getting past someone may be turned into a pedagogical event. Responding to a tactile gesture (line 1) with an attempt to make an utterance displays that the student does not know any word for 'butt', 'buttocks' or 'backside' in Swedish. She turns to other students ( $c f$. M. H. Goodwin, 1997) and asks how she can say 'butt' in Swedish (line 3). As she seeks help to find an appropriate equivalent for the word (lines 3 and 6), the sequence gradually expands not only in size but also in type of activity. The participation framework (Goffman, 1981; C. Goodwin, 1981), which involves only two interactants at the beginning of the encounter, soon becomes accessible to the 
others (Goffman, 1963: 154), and the topic shifts from a word search to appraising backsides and making jokes.

When offering 'candidate suggestions' (cf. Lerner, 1996, 2002) for 'buttocks' or 'backside' in Swedish ('skinka' or 'rumpa', in lines 7 and 8), the students begin to treat the topic at hand as a joke (line 8) and, thus, laughable (Sacks, 1974). So, beside the fact that a Swedish gloss for 'backside' is sought, a normative approach to the choice of word ('skinka' or 'rumpa') arises as well. Moreover, a social orientation to the sensitivity of its use becomes the business of interchange (the participants all together laugh at the topic, lines 8-13).

This sequence shows that a tactile event turns into a learning opportunity, as well as some other social practices. This is an example showing the embodied accomplishment of a learnable in a classroom interactivity. As it is instantiated above, and it will be underscored throughout this dissertation, the actions coconstructing the burgeoning of the learnable are embodied actions lodged in a larger activity, developed in the granularity of the organization of their sequence, and contingent upon the endogenous detailed production of actions. So, what this research project is concerned with is the order of the organization of practices investigated from within (Garfinkel 1967, 1996, 2002: passim) where members use their own methods in accomplishing learnables in classroom interactivities.

\subsection{Aims and research questions}

In the last couple of decades or so, research on second language learning has begun to micro-analytically attend to interaction and participation in naturally occurring events as the corner stone of language learning processes (see e.g. Firth \& Wagner, 1997, 2007; M arkee, 2000; Seedhouse, 2004; Y oung \& M iller, 2004; M ondada \& Pekarek Doehler, 2004; K oschmann, Zemel, Conlee-Stevens, Y oung, Robbs, \& B arnhart, 2005; Hellermann, 2007, 2009; Seedhouse, W alsh \& Jenks, 2010; Hall, Hellermann $\&$ Pekarek Doehler, 2011, etc.). In this still relatively new tradition, the two fields of linguistics and kinesics which have long been claimed to be interrelated in human interaction (see e.g. Condon \& Ogston, 1966, 1967; K endon, 1977, 1990; Goodwin, 1981; M cN eill, 1992; Streeck, 1996, 2009) are considered 
in the social organization of second language learning (Gardner \& Wagner, 2004; Lazaraton, 2004; Olsher, 2004; M ori \& Hayashi, 2006; Churchill, Okada, Nishino $\&$ A tkinson 2010; M ortensen, 2011; Seo, 2011, etc.).

The use of different modalities in learning has now been shown to be at work in instructional activities involving manual skills (e.g. Ekström, Lindwall \& Säljö, 2009; Lindwall \& Ekström, 2012), dance skills (e.g. K eevallik, 2010), music skills (e.g. Nishizaka, 2006; Szczepek Reed, Reed \& Haddon, 2013), even developing knowledge in archeology (e.g. C. Goodwin, 2003), mathematics (e.g. Radford, 2003; Radford, Demers, Guzman \& Cerulli, 2003), geography (e.g. Mogk \& Goodwin, 2012), or in academic supervision meetings (e.g. Svinhufvud \& Vehviläinen, 2013). The same thing can be observably reported as happening in second language learning classrooms.

In this research project, I will focus on teacher-student talk in language learning classrooms. The setting that I have chosen to study is a series of language classes designed for foreigners in Sweden to learn Swedish as a second language. This institution is called Swedish for Immigrants (SFI). The classes have been videorecorded for a detailed analysis.

The analysis is aimed at illuminating some aspects of the procedures involved in classroom interactivities and their local achievements. The focus is on embodied actions and endogenous achieved details of procedures leading to the production of linguistic items or expressions proffered as learnables. This procedure is not just built on talk, but rather on its intertwinement with other semiotic resources.

Accordingly, focusing on practical actions, I will provide some interactional accounts describing the members' practices (Garfinkel \& Sacks, 1970/1986), and specify their methods for the local endogenous production of teachable moments and learning opportunities as instructably achievable phenomena. This research project contributes to the large corpus of classroom interaction studies, which al ready exists within the fields of education, language learning and classroom discourse (e.g. Bellack, Kliebard, Hyman, \& Smith, 1966; Sinclair \& Coulthard, 1975; M ehan, 1979; Cazden, 1986, 2001; M arkee, 2000; Seedhouse, 2004; Walsh, 2011). 
The research project also contributes to a better understanding of the design of actions, the role of participants, e.g. their competence, in the practical achievements of learnables. All of this can be exhibited in the methods that the participants in a classroom setting deploy for such achievements through their concrete methods, and the accountability of their practical actions (see Garfinkel, 1967: 1). This project specifically aims to address the following questions:

- How do learnables emerge in second language learning interactivities?

- How are interactivities in which learnables emerge socially organized?

- What methods and modalities are used by teachers and students in the accomplishment of learnables?

\subsection{Learnables}

The achievement of learnables in classroom interactivities consists of social sequential actions that introduce them ( $c f$. M arkee, 2000; Seedhouse, 2004), clue them ( $c f$. M cHoul, 1990), highlight them ( $c f$. C. Goodwin, 1994), or put them in the focus of attention in passing or in full-blown sequences (see Study 3). The entire character of this accomplishment lies in the episodes of interactivity, that is, in an ongoing course of action (see Study 1 and 2).

Learnables have their sources everywhere. In pedagogical settings, they are what is in the focus of pedagogy as formal products displayed or oriented to as relationally necessary, or adequately relevant, for all practical purposes, to perform or accomplish particular activities. Here, it will be shown that the opportunities for learnables to emerge are interactional accomplishments achieved through the use of diverse semiotic resources, which are at the interactants' disposal and deployed for those accomplishments.

It has been discussed before (see e.g. Holmqvist, Tullgren \& B rante, 2011: 68) that an 'intended' object of learning may not necessarily be the one 'enacted' and 'experienced' in the setting by the teacher and the pupils together (see also Seedhouse, 2004). This research project attends to the reality of how learnables are experienced, and focuses on the procedures in which the operations on talk and other conduct lead to the emergence of learnables. 
In the analysis of what is being taught and learned, the formal products as objects of learning are conventionally considered as discrete independent forms with some particular properties; for example, in language learning, they are lexical items, syntactical phrases with some semantic properties, etc. That is, the metatheory of the nature of (a) language is that of sets of abstract forms. These formal objects can be quantified, generalized, and established as frequently used items with objective meanings and functions, etc. The students in their interactional coengagement with their teachers (and/or their peers) in a learning environment somehow see them, and are instructed to see and understand them in that way on the occasion of their occurrences. The methods that are used by the participants in the interactivities, in and through which some linguistic objects are offered and understood as learnables, are going to be observed and analytically described.

The word 'learnable' is preferred to 'object of learning' in order to stress that a phenomenon (whatever that is) is not just introduced as an abstract something recurrently achieved in many other situations, having inherent features, function or meaning. It becomes instructably observable as something to learn, under a particular circumstance and through a particular procedure. Its salience is brought to being in that activity. The emphasis in this research project is placed on how teachable moments or learning opportunities are achieved on a particular occasion to offer something as a learnable.

What is being studied here is how learnables in searching for a word, in describing an event, in formulating the telling of a story or a description of something, in a correction, in a reformulation, etc. are achieved in an embodied way, on the actual occasion of their occurrences.

A learnable, or the opportunity of its teaching and learning, therefore, is not looked at, or investigated as something mass-produced, premeditated and 'as the work of a population that staffs its production', but how it 'exhibits its population' (Garfinkel 1996: 5), i.e. how it gives life to its generalizability qua achievement, as an achievable phenomenon, occasioned, displayed, and recognized in the particular sequential course of an activity in the organization of its setting. 


\subsection{Outline of the dissertation}

The research project is based on four separate studies that have been conducted on the accomplishment of learnables. The sources and the resources used in the achievement of learnables, the organization of inter-actions, and the embodied practices involved in the activities, within which learnables emerge, are examined. The perspective employed in these studies takes on dialogical (interactional and contextual - see Linell, 1998, 2009) and praxeological (ethnomethodological and conversation analytical - see Garfinkel, 1967, 2002; Garfinkel \& Sacks, 1970/1986; Sacks, 1992a,b) approaches; I use multimodal action-based interaction analysis (see e.g. C. Goodwin, 1981, 1994, 2003, 2013; Heath, 1984; M ondada, 2007a, 2010; L uff \& Heath, 2012; B roth \& M ondada, 2013) to explicate how, in situ and in vivo, actions are accomplished by the participants (see also Garfinkel, 2002: 167). Through this approach, some careful, detailed, and multimodal data analyses will be presented.

The chapters leading up to the studies include the above introduction to the general and specific aims of the studies (1), which will now be followed by a presentation of the research background (2), the data used (3), the theoretical and methodological framework (4), the concise results of the studies and (5), at the end, some concluding remarks (6). 


\section{Approaches to language learning}

In the following sections, I will first present a background for socially oriented approaches to learning in general, and to language learning in particular. I will then provide an overview of the studies using EM/CA in educational settings, and will review some studies on interactivities in classrooms. I will also show how the application of EM/CA will be helpful in demonstrating the use of embodied practices and examining their use in the context of language learning. Finally, I will review relevant parts of the research on Swedish for immigrants (SFI).

\subsection{The social turn in language learning research: A historical account}

M odern research on learning has its roots in social and psychological studies on education in the beginning of the twentieth century (see e.g. Delbos, 1899; Dewey, 1915; Piaget, 1926; Thorndike, 1931). Through its development in the second half of the twentieth century, however, instead of concentrating on the practices of learning, investigation on learning turned into theorizing about learning, particularly about language, as a code-learning (see R. Ellis, 1990).

During the 1970s and the 1980s, researchers interested in both sociology and anthropology made fresh attempts to find new methods and theories for the educational field, including language use and its learning (Gumperz \& Hymes, 1972; Hymes, 1977, 1980; Cazden \& Hymes, 1978; Ochs \& Schieffelin, 1979; Schieffelin \& Ochs, 1986, to name a few). Language learning, however, was still overwhelmingly under the influence of traditional psychology and mentally oriented hypotheses both in first and second language learning (e.g. Selinker, 1972; R. Ellis, 1990; Gass, 1996; see a more elaborate discussion in Tomasello, 1998: vii-xxiii). This, however, did not last long. The description of classroom discourse (see e.g. M cHoul, 1978; M ehan, 1979; K ramsch, 1983; Cazden, 1986; van Lier, 1988) began to show the importance of humanistic and sociological approaches to classroom and learning environments. The bottom line was that what is at issue in the educational field are the communicative events and interaction. This new focus on communication and interactional efforts in pedagogical environments 
eventually made do even among psychologically oriented language learning researchers who also highlighted the impact of social factors in their proposed theories and hypotheses (e.g. Long, 1981, 1996; Swain, 1985; V aronis \& Gass, 1985; Pica, Y oung \& D oughty, 1987; Swain \& Lapkin, 1998, etc.).

Finally, it took a decade or so until the time came when the call for the revision of the congruence of theories and methods with the reality of language use in language learning was taken seriously (see e.g. Block, 1996, 2003; Firth \& W agner, 1997; $c f$. Lave \& W enger, 1991; Tomasello, 1998). The effect of this shift in the paradigm of research on language learning has resulted in a growing number of papers and books that are being published from an EM/CA perspective (see section 2.2 below; see also section 4.2. for the theoretical discussion).

\subsubsection{Learning as a social practice}

One of the first attempts in the twentieth century to respond to the inquiry into the howness of language learning in a modern ethological sense was made by Skinner (1957), who defined learning language as learning 'verbal behavior' by means of instrumental conditioning (Tomasello, 2003: 2). An alternative to such a theory was made famous by Chomsky (1959, 1987/1993) who claimed that language learning is dependent on a biologically inborn faculty ('innateness') and its hidden system for shaping universal language grammar in the mind/brain.

Traditional cognitivism, moreover, had also fed into the emphasis on the mental systems in human intelligence and psychological development. Traditional cognitivists aligned with the artificial intelligence researchers to consider 'information processing as the central activity involved in intelligent behavior' (Estes et al, 1983 in Skinner, 1985; cf. K rashen, 1981). Putting the embrained mind in the center, they would seek their answers to any question related to language development from within and inside the mind/brain rather than anything from outside (for a more elaborate discussion, see also Linell, 1998). For those influenced by such a view, learning was nothing but a mental phenomenon (see e.g. the debate between Piaget and Chomsky in Piattelli-Palmarini, 1980). 
The importance of the mind-body relation in learning and cognitive development, however, is undeniable (see Piaget, 1961; Vygotsky, 1978). From a psychological perspective, learning has some psychogenetic roots (Piaget, $1936 / 1952,1961,1980)$, implying that it comes about through the equilibrium and disequilibrium that occurs between the maturation of body and mind, the physical experience of the individual and his/her social interaction (Piaget, 1961). Such states and processes are also socio-historically and socio-culturally mediated (V ygotsky, 1978, 1986). There is no doubt that the environment (the social factors) feeds the different stages of learning progression, if it does not shape it from the very beginning (see Tomasello \& Zuberbühler, 2002; $c f$. the ontogenetic view of language development, in Tomasello, 2003).

Therefore, contrary to the nativists' view of the prewired concepts in the mind or the traditional cognitivist's mind-centered view ( $c f$. A. Clark's problematization of the conception of mind in classical cognitivism, 1989: chapter 1), the direction of action for learning is not merely from within the mind to the outside, as manifest in the perceivers' individual display of what they have 'in mind'. There is also the effect of environment and others on their behavior. That is, there is a social and dialogical aspect to the process of learning, a relational dimension to the engagement of the learners with the world and others (see relationism in dialogism in Linell, 2009: 24). One learns something from a source (others and the surrounding world), in one's engagement with that source, with the available resources (cf. C. Goodwin, 2003, 2013; M ogk \& Goodwin, 2012; M elander, 2012, etc.); and one is socially accountable for one's acts upon the world.

This view can be explained through some tangible instances. A common conviction about learning seems to be that it is an individual process with a beginning and an end (Wenger, 1998: 3), when, for example, one says, 'I am learning $X^{\prime}$. But nonetheless, this is a social phenomenon as much as it is an individual one. If there is any achievement in doing learning, it is certainly achieved in a social context in relation to the surrounding materials, ecological environment, and other conspecifics, by making some certain observable moves/acts upon the world for its accomplishment (reading, writing, seeing, 
hearing/listening, operating on something, etc.). In this activity, the 'successive and sequential constructions' (Piaget, 1980: 25) are not merely part of a mental process or its product; they are, in reality, a progressive social actualization of actions made by learners, traceable as an observable-reportable change in their social conduct.

The ending process of learning may be conceived when one commonsensically says, 'I learned $X$ ', 'I now know $X$ ', 'I now know how to do $X$ ', 'I am now able to do $X$ ', 'I am now an expert in (doing) $X$ ', etc. The grammar of the words 'knowing', 'being able to', 'having the skill of', 'understanding', etc. and 'doing' are close to one another (see W ittgenstein, 1953/2009: §150, p.65; see also Mondada, 2010; Macbeth, 2011). These utterances may indicate some accomplished actions, but they certainly pertain to particular circumstances, and are subject to some social expectations. What if a person cannot perform what he claims he knows? This is exactly what makes learning a social phenomenon.

Not knowing something cannot always be translated into a defect in one's mental ability, but it is simply a display of not performing as one is expected to. Therefore, the process of learning and its accomplishment are not a once-for-a-lifetime achievement but a recurrent display of knowing in social situations, that is, the ability to participate in relevant situations, and showing it on every single occasion.

Researchers who deal with learning usually deal with certain aspects of learning such as knowledge, knowing, and competence which are tested and assessed by 'doing' things. Seeing learning as a social phenomenon means that these aspects do not have platonic existence only through concepts and ideas, but they are realized in social life as perceived and conceived in interaction with the umwelt. Knowledge in the shape of 'sensibility' and 'understanding' is not just the product of an individual mind but also an empirical achievement (Holquist, 1990: 4), as the outcome of our sense-experience pragmatism. Developing such an idea would give rise to seeing all-important parts of human 'consciousness' and cognition also through socio-interactional/cultural/historical lenses. 
Cognition is thus constructed in a social and embodied way (Goodwin, 1994, 2000b, 2013; Maynard, 2006; Streeck \& Jordan, 2009). It is not just a psychologically developmental structure (cf. Piaget, 1961: 281) or a mental construct whose development is mediated by tools, speech and other available resources, (cf. Vygotsky, 1978, 1986). But, it is also a social achievement, distributed and co-produced as part of human social environment, and human conduct, as an observable system socially shared in social activities (see also Schegloff, 1991; Streeck, Goodwin \& L eB aron, 2011).

In a similar vein, learning a language, if it means gaining competence and building capacities for knowing and doing things with language, is certainly done socially. If researchers are concerned with what is acquired and how it is acquired by individuals, they are not only and solely talking about individuals' internal mental activities, but how individuals, in interaction with the world, socially accomplish those properties.

Within a socially-oriented approach, research on language learning is required to explain how the ability to use language is initiated, developed, interpreted, corrected, etc., and how this occurs in social reality. One seeks the answers to these questions in and through studying the observable and reportable communicative events ( $c f$. Garfinkel \& Sacks, 1970/1986) involving the use of natural language in different social settings, educational environments, etc.

$L$ anguage learning is not about an ideal environment and an ideal, generic mind, which processes some exposed 'appropriate input', 'comprehensible' data, etc. The world a language learner lives in is far from the one that language researchers call the 'appropriate one', with the 'appropriate assistance' (Ohta, 2000: 51), or 'appropriate input' (Krashen, 1981), resulting in appropriate 'comprehensible output' (Swain \& Lapkin, 1998). The reality of what is happening to the learners in real life is different.

In this way, learning becomes a social procedure in and through which something is oriented to and accounted for and understood as something hitherto unfamiliar. That is, one can display understanding, knowing, and being able to do something new through social acts. Disregarding learners' methods and their social 
environment (social relations, verbal and nonverbal context, background, biography, etc.), which are part of the individual's competence-building procedure, conceals at least part of the truth, if not the whole truth, about how learning is actually achieved.

In other words, there are different paths in language learning research. One way to present the acquisition of language is to model it through a hypothetical mental process and map it onto an ideal learner. A nother way is to ask how real learners learn what they learn through their methods, their performances, and their social conduct.

\subsubsection{Interactivities: An area for language learning research}

The cognitivist models of learning are based on mental processes defining language as a set of systematically interrelated, rule-governed mental codes and concepts lodged in the mind/brain (cf. Chomsky 1987/1993). They are clearly distinguished from their socially oriented rivals seeking their answers about language learning in a larger area of language use (see A tkinson, 2011; Hall et al., 2011). The basic principle of this alternative approach is that sharing a language is not merely sharing codes; rather it is engaging in a cooperative enterprise (Vygotsky, 1978; Linell, 1998; Tomasello, 2003, 2008), building a common conceptual ground (H. Clark, 1996), and sharing forms of life (Wittgenstein, 1953/2009).

Central to this socially oriented approach and its concomitant theories and methods of research is a careful attention to the concept of 'context' (Goodwin \& Duranti, 1992), and looking anew at humans' intersubjective world (Schutz, 1932/1967), and the use of language in human interaction as 'the primordial site of sociality' (Schegloff, 1987: 208).

In language learning, the issue is not just grossly pointing out the significance of humans' social situations, communicative needs and abilities, their social variations, culture, and individual differences in learning (e.g. Hatch, 1978; Long, 1981, 1996; Swain, 1985; Lehman \& Jones, 1987). What one needs to do in research is to show how these issues are and become the social reality of language 
learning situations. That is, the research shall not keep itself just in the real $m$ of the metaphor of acquisition ( $c f$. Sfard, 1998), but investigate learning in the reality of co-participation in interactivities. One cannot remain tied to the assumptions of traditional mentalist models (Ortega, 2011: 167; cf. Gass \& Selinker 1994/2008; Chomsky, 1987/1993), but one must turn to the reality of language use and social aspects of language learning.

Revisiting the assumptions behind the theories of learning (Block, 1996) may be done through a balance between theories and methodologies (Firth $\&$ Wagner, 1997), and it is only possible through the collection of empirical real data from various settings and interactivities. Firth and Wagner (1997) accordingly invited researchers in the second language area to be more concerned with the context and interactional particulars of language use, not merely to rely on a priori theories, but instead, to take an emic perspective (Pike, 1954: 8; cf. Garfinkel \& Sacks, 1970/1986) while dealing with real data.

Firth and Wagner (1997: 286) also advanced arguments for the expansion of the data sets to involve a wider range of data, ranging from formal and experimental environments to various non-formal, non-educational, and empirical learning environments. In short, they asked for a social turn in second language learning research. This view has its roots in a dialogical (interactional and contextual; see Linell, 2009) and praxeological (Garfinkel, 1967, 2002) approach to language learning and has benefited a lot from ethnomethodological conversation analysis (see Garfinkel \& Sacks, 1970/1986; Sacks, 1992a, b; see section 4.2, and also Study 4).

Therefore, in the social approach, learning is to be reconceptualized and second language learning reinstituted insofar as to change the way of looking at learning not only as a private individual achievement, but as a social accomplishment in a variety of social situations. It would certainly help us to see and, eventually, hypothesize better than before, for instance, what second language learners/users accomplish and how they do it in their interactivities together with their teachers, or their peers in the classroom (e.g. Markee, 2000, 2008; Pekarek Doehler, 2002; Seedhouse, 2004, 2005; Kasper 2004; Kasper \& Wagner, 2011; 
A mir \& Musk, 2013; M usk, 2013; Kunitz, 2013; M ajlesi, 2014, etc.), or with others outside of the pedagogical environment in what is known as second language conversation (Brouwer \& Wagner, 2004; Brouwer, Rasmussen \& Wagner, 2004; Gardner \& Wagner, 2004; Kurhila, 2004; Plejert, 2004; M ori \& Hayashi, 2006; Firth, 2009; Cromdal, 2013).

\subsection{EM/CA and language learning activities}

Ethnomethodological conversation analysis (EM/CA) with its principles and proposed methods of examining orderliness in local-interactional activities (Garfinkel \& Sacks, 1970/1986) from its early years began to be adopted as a useful research perspective and an analytic tool to investigate learning situations in classrooms (Erickson, 1973; M cHoul, 1978, 1990; M ehan, 1979; Gustavsson, 1988; M acbeth, 1990, 2004, among others).

Drawing on EM/CA methodological principles, Erickson (1973) and, then, B remme and Erickson (1977) and Erickson and Schultz (1978) pioneered in what they called the micro-ethnography of schooling and classroom activities. They paid attention to the 'oddness' of the 'ordinary' everyday behavior that 'we as members take for granted' (Erickson, 1973: 16; cf. Schutz, 1932/1967; Garfinkel, 1967), namely, the use of language, the interactional activity with the use of both verbal and nonverbal conduct (cf. Goffman, 1956, 1963). For instance, B remme and Erickson (1977: 153-4), by their detailed observation and description of classroom interaction, explained that the accepted social behavior in the classroom requires that participants should be able

'(1) to determine what social situation, or context, is happening now, from moment to moment within the occasion;

(2) to interpret the social meaning of others' behaviors in the light of the social situation happening now; and,

(3) to identify and produce, from among one's 'repertoire of behaviors, those forms considered appropriate alternatives now, in 'this' social situation.' 
What they observed is how activities are organized in classroom social situations. They underscore the significance of understanding these activities from within (Garfinkel 1967, 2002). This is also comparable to views on 'communicative activity types' (see Linell, 2009; see also Levinson, 1992, 2013). John Gumperz (1992: 43-44) likewise defines the concept of activity in this way: 'M y basic assumption is that all understanding is framed understanding, that it ultimately rests on contingent references made with respect to presuppositions concerning the nature of the situation, what is to be accomplished and how to be accomplished. The term activity can be seen as a cover term to suggest what these presuppositions are.' (italic original).

Even though challenged by traditional views on language learning, especially in cognitivist traditions (see Seedhouse, 1998; He, 2004), the call for attention to the context and circumstances of language learning procedures (see Block, 1996; Firth \& Wagner, 1997), and to EM/CA and its conversation analytic principles found their ways also in second language research (see e.g. M arkee $\&$ Kasper, 2004; Y oung \& M iller, 2004; Firth \& Wagner, 2007; Kasper \& Wagner, 2011, inter alia).

Currently, there is a growing body of research in the field of second language learning in which researchers apply EM/CA to their studies and they not only attend to the talk but also to the whole range of semiotic resources in learning activities (see Olsher, 2004; Slotte-L üttge, 2005; M ori \& M arkee, 2009; M arkee, 2011; M elander \& Sahlström, 2009).

Focusing on interactional activities, some studies have now examined the issue of the allocation of turns in classroom participation (e.g. M cH oul, 1978; Sahlström, 1999), as well as the issue of socialization in classrooms (e.g. Cekaite, 2006). Different exchange systems of practices ( $M$ arkee, 2000), and different pedagogical contexts in classrooms (Seedhouse, 2004) have also been studied. Correction in pedagogical activities (e.g. McHoul 1990; Macbeth, 2004), and even nonpedagogical activities for second language speakers (e.g. Kurhila, 2001; 2006; Plejert, 2004) have been investigated as well. Different classroom activities have also been examined such as word searches (Brouwer, 2003), vocabulary 
explanation (L azaraton, 2004; M ortensen, 2011), grammar teaching (Churchill et al., 2010; Study 2).

Applying a conversation analytic framework on language learning situations (pedagogical and non-pedagogical), studies have shown how second language learners accomplish meaningful social actions, showing and developing their interactional competence in various social activities (see Hall et al., 2011). They have shown that what is known as communicative competence is not just a cognitive property of individual competence, but a social display of understanding and applying social practices in a face-to-face interaction (ibid. p. 15).

With the application of EM/CA to second language learning classrooms, attention is drawn to the detailed accomplishment of interactivities through embodied practices such as bodily movements, gestures, gaze, and other nonverbal conduct, and also the use of artifacts such as whiteboard, papers, documents, computers, etc. in the teacher's vocabulary explanation (Lazaraton, 2004; M ortensen, 2011), teaching grammar (Churchill et al., 2010; M ajlesi, 2014), pronunciation correction (B roth \& Forsberg Lundell, 2013), students' group planning, pre-task planning and the actual implementation of tasks as a coconstruction process (e.g. K unitz, 2013; M usk, 2013), etc.

$M$ arkee $(2000,2004)$ describes the properties of talk in different classroom activities. Markee and Kasper (2004) prove that there is a range of different exchange systems in classroom talk. Similarly, Seedhouse (2004) demonstrates how in task-based learning, the pattern of interaction in form-focused language lessons is more 'precise' than in meaning-in-fluency focused lessons where the organization of interaction becomes less 'narrow and rigid' (ibid, p. 111). Mori (2002) discusses how students working in pairs use the instructional design of a task as a resource to complete the task, and al so to create learning opportunities ( $c f$. $M$ arkee, 2004, for different 'classroom talks'; see also K unitz, 2013). A part from the design of talk and activities, the design of turns has al so been studied. Repair in classrooms has been a frequent research topic. It has been shown that even though it is still dispreferred (see Macbeth, 2004), other-initiations of repair are very 
common in classroom talk (M cHoul, 1990; $c f$. Egbert, 1998 in oral-proficiency test data; $c f$. K asper, 2009; Hellermann, 2009).

Finally, EM/CA research in the educational field can now be found in educational discourse of various kinds. They not only attend to language but especially also to embodied practices and context, which are mutually constitutive (see e.g. Goodwin \& Goodwin, 1992). EM/CA has now been applied to music classes and rehearsals (e.g. W eeks, 1996; Nishizaka, 2006; Szczepek Reed et al., 2013), dance lessons (e.g. K eevallik, 2010), educational practices in laboratory work (Lindwall \& Lymer, 2008), design reviews for architectural education (Lymer, Ivarsson \& Lindwall, 2009), medical classes (K oschmann \& LeBaron, 2002), training of dentists (Hindmarsh, Reynolds \& Dunne, 2011), and surgeons (Koschmann, LeBaron, Goodwin \& Feltovich, 2011), handicraft education (Ekström et al., 2009; Ekström, 2012; teaching crocheting in Lindwall \& Ekström, 2012), or instructing how to repair bikes (A rnold, 2012).

Even though research on language learning from within a conversation analytic perspective has its own critiques for not focusing on cognition (e.g. He, 2004), the application of EM/CA on the procedures of learning activities helps understanding how cognition is gained access to or displayed, talked about, operated on, shaped, etc. (see Mondada \& Pekarek Doehler, 2004); because 'cognition, contra some widely-held beliefs in academic circles, has been concerned within CA and Ethnomethodology from its early days' (Gardner, 2013: 607, italic original). A s Heritage (2005: 188) puts it, a 'cognitive process is not something which speakers simply report, it is also something which they embody in talk-in-interaction.'

\subsection{The body, talk and the material world in pedagogical activities}

The interest in body movements and gestures has a long history. The earliest systematically recorded research on gestures, to the best of my knowledge, goes back to the Roman orator Quintilian in $100 \mathrm{AD}$, who wrote extensively on gestures as 'rhetorical' devices (see Kendon, 1997: 110). In a more modern psychological sense, perhaps it was W undt (1904/1973) who was among the pioneers writing and lecturing about gestures as part of his formal lectures on language in the second 
half of the $19^{\text {th }}$ century. His psychological studies of gestures and their relations to the inner emotional states of the human mind, and the innate link between gesture and the origination of language were later published in Die Sprache ('language'), one of the two volumes in his series of Völkerpsychologie ('folk psychology') in 1904.

Mead (1910: 398) also talks about 'a conversation of gesture', where he describes gestures in animals 'as a class of conduct' within social conduct. Later studies on gestures were more on cultural issues defining gestures as systematically based on some socially shared patterns (see e.g. Efron, 1941; Ekman \& Friesen, 1969). M oreover, the advent of video recording helped scientists to see more of gestural effects in human communicative abilities, for instance, in the early efforts of Birdwhistell and Scheflen (see Condon \& Ogston, 1966: 338).

With the aid of technology, the interconnectedness of body movements and speech could be closely examined in video-recordings. Condon and Ogston (1966, 1967), for instance, in their studies based on video-recordings show how body parts are sustained or change their configurations together in synchrony with language production (see also Kendon, 1970). Examining the "units' of behavior at the micro level' (Condon \& Ogston, 1966: 341), other studies have also shown that body movements are not only in coordination with speech, but with the body and speech of another speaker (see K endon, 1977). B odily conduct, gaze and facial expressions are sensitive and in synchrony with the actions made in interaction even across bodies (e.g. showing 'affiliation needs', etc., K endon, 1977: 53). This is confirmed by C. Goodwin's $(1979,1981)$ study of gaze in interaction, where he shows how speakers and listeners use gaze as a mechanism to show their engagement and disengagement in interaction, which affects the speaker's speech production.

The study of embodied actions in human social interaction has helped us to understand the correlation of the use of gestures with cognitive development, for instance, the speaker's (embodied) thought, etc. (M cN eill, 1992; G oldin-M eadow, 2003; Streeck, 2008; inter alia), and also to understand the communicative content-intent of gestures in different communicative events (K endon, 1977; 
Streeck, 2008; A ndrén, 2010: chapter 2; inter alia). These studies have shown the relevance of gesture studies for 'theoretical issues in cognition, language acquisition, and conversational processes' (K endon, 1997: 110; see also A libali et al., 1997).

Moreover, Marjorie and Charles Goodwin's studies on embodied actions in different types of interactivities with regard to the sequential analysis of communicative actions and turns in talk, have given us a useful account of the functions of gestures in interaction. They show how interactive cooperation of the hearer (recipient/addressee) with the speaker through various embodied practices (verbal and nonverbal resources) would result in the co-construction of a variety of actions, e.g. in the production of a turn (C. Goodwin, 1981), in the display of an assessment (M. H. Goodwin, 1980), in word searches (Goodwin \& Goodwin, 1986), or in disagreements (Goodwin \& Goodwin 1987; see also M. H. Goodwin 1990). They have also shown that how larger activity projects are talked into the current activity, and how important aspects of context are attended to in turn constructions. Using all these resources, participants collaboratively shape a coherent system of action and context for the activity in hand (Goodwin \& Goodwin, 1992).

C. Goodwin (1994) shows how competent use of embodied practices in operating on the material world can be constitutive of the 'object of knowledge'. The production of material representations is shown (see also C. Goodwin, 2000a, b, c, 2003) to be crucial to the social organization of the ways of seeing and understanding objects of knowledge that which he calls 'professional vision' (Goodwin, 1994). The use of embodied practices and available material resources for making actions and transforming knowledge is what C. Goodwin also underlines in his later studies (see e.g. C. Goodwin, 2013; cf. M elander, 2012).

C. Goodwin's findings in the formation of human action with a symbiotic link to its surrounding environment are consistent with the view of contextualized, socially organized, situated learning (Erickson, 1982; cf. Lave, 1988), and the view of cognition as embodied and distributed (M aynard, 2006; Streeck \& J ordan, 2009; Streeck et al., 2011; cf. Hutchins, 1995; Clark \& Chalmers, 1998). 
In other instructional activities, the intertwinement of talk, body and artifacts has been elaborately demonstrated and discussed in various settings. In his study of an instructional activity in an archeological site, C. Goodwin (2003), demonstrates how the body and the soil in the environment are used as resources in which an expert archeologist shows to a novice where to look and what to look at in the soil in order to transform something as apparently trivial as dirt into a visible cultural object, significant to the archeologists. This is done in a leading-and-following instructional sequence. What the expert does is show what should be seen and operated on over the soil, and what the student does is implement those movements in the soil. This leading-following course of action has some consequential effects on understanding the function of bodily action, especially gesture, which is also going to be underscored in this study (Studies 2 and 3). C. Goodwin argues for the consideration of other semiotic resources in the investigation of the use of gestures in communication; that is, gestures and other semiotic resources become so symbiotic as to be composing one action-unit within the physical environment as well as the interactional context for practical purposes in the circumstances of their occurrence.

The importance of gestures and other resources in the environment in architectural education has been emphasized elsewhere (LeB aron, 1998; LeB aron \& Streeck, 2000; M urphy, 2004, 2005; Lymer et al., 2009). Lymer et al. (2009), for example, show how in an architecture design studio the review of the design in presentation is used for pedagogical purposes, and how the practices of presentations are mediated by various embodied and artifactual resources. The accomplishments of instruction and professional vision are done through the temporally organized and spatially situated presentation.

Nishizaka (2006), who studied a music class, shows how instruction and correction in music practices are done through embodied practices ( $c f$. W eeks, 1996). In a music rehearsal, in the interactivities for music coordination, it is also exhibited that leading and following social actions are dependent not only on the talk, but on embodied practices. Through such practices, moments for learning may emerge (see also Szczepek Reed et al., 2013). 
Likewise, Keevallik (2010) shows how dance teachers reuse and recycle their students' dance moves in a fashion that she calls 'bodily quote' so that they may correct the students' moves through speech and embodied practices. The bodily actions are the necessary parts of the instruction demonstrating the right and wrong dance moves. At the same time, from an interactional point of view, they display a heightened co-participation ( $c f$. Sidnell, 2006) in interaction with the students.

Lindwall \& Ekström (2012) show how following the teacher's instruction is also achieved through a close interactive collaboration between the teacher and the student while teaching the manual skill of crocheting. Responding to the teacher's request to follow the instruction is not just done by accepting it, but through a visible display of action, which is the witnessable evidence of understanding or non-understanding of the instruction. This is used as grounds for follow up actions such as corrections. Doing part of the manual work as showing understanding and also learning (not just claiming it; see Sacks, 1992b: 252) -, is also shown by Hindmarsh et al. (2011). They, too, demonstrate that, in an educational setting such as clinical dental training, understanding an instruction is made relevant through performance and not just claiming understanding. The display of understanding is done through embodied practices acting on the material world (see also M ondada, 2010).

E mbodied practices and the use of artifacts are likewise considered significant resources in learning in other theoretical frameworks such as socio-cultural or socio-cognitive perspectives (e.g. L antolf, 2000, 2011; A tkinson, 2002; Churchill et al., 2010; Swain, Kinnear \& Steinman, 2011, among others). Studying mathematics classes, Radford (2003; Radford et al., 2003) problematizes the issue of 'objectification of mathematical knowledge'. He observes how tools and speech give 'a corporeal and tangible form to knowledge' (ibid, p. 41).

Churchill et al. (2010) show the significance of overall attention to the coordination of embodied actions and the use of a worksheet in teaching a grammatical component in second language tutoring. Providing evidence for a socio-cognitive theory of learning (see Atkinson, 2002), they underscore the situatedness (Lave, 1988), and the distribution of cognition (Hutchins, 1995) across 
mind, body and environment ( $c f$. V arela, Thompson \& Rosch, 1991; Clark \& Chalmers, 1998). They also reconfirm C. Goodwin's (2003) finding that the meaning of gestures (here in teaching grammar) is in a symbiotic relation to its immediate physical environment.

The affordances of embodied practices ( $c f$. Gibson, 1979) are also acknowledged in different experimental studies. In learning/instructing events, it is now clear that gestures are helpful for learning among both children and adults (e.g. Church and Goldin-M eadow, 1986, Gullberg, 1998; McC afferty, 2002; Gentner \& Goldin-M eadow, 2003, Singer and Goldin-M eadow, 2005; Gullberg, 2008). Nonverbal actions are proved to be concomitant with, influential in or correlated with learning activities. There seems now to be a consensus that the utilization of gestures improves learning in general (Singer and Goldin-M eadow, 2005), and it is used as a useful resource in language learning in particular (see also Lazaraton, 2004; cf. B rown \& Gullberg, 2010, 2011).

Even though the number of studies on embodied practices and the use of artifacts in language learning situations in an EM/CA tradition is increasing, this line of research is still young and there are many practices in doing teaching and learning which are not yet 'analytically described' (i.e. the description of practical organization of this system, see e.g. Sacks, 1963) with empirical data.

Among nonverbal conduct, such as gaze, posture, facial expressions, movements of torso, legs, hand gestures, head movements, etc., and prosodic features, the studies presented here only describe a limited number of gestures in embodied practices used for pedagogical purposes. The detailed analysis of other embodied conduct is beyond the scope of these studies. Likewise, in showing the importance of material resources, even though there are many artifacts exploited in classroom activities for pedagogical purposes such as whiteboard, overhead, pens, papers, various sorts of documents (handbook, notebooks, course books, etc.), computers, mobile phones, tablets, etc. the studies here will not analyze the use of any wide range of artifacts in classroom interactivities. The functions of most of these artifacts in accomplishing different activities in the classroom may become topics for future research. 


\subsection{A detailed study of interactivities in classroom discourse}

The discourse analysis proposed by Harris (1952) aimed at discovering structures beyond sentence boundaries, emphasizing the distributional analysis of linguistic elements from phonology to syntax. This, however, could not respond to the demands for the analysis of communicative events in classrooms (Hymes, 1964). It was not until the late 1960s and then during the 1970s that the impact of studies about language and context, and their mutually constitutive relations (see e.g. Goffman, 1956; 1967, 1974; Labov 1966; Garfinkel, 1967; Garfinkel and Sacks, 1970/1986; Sacks, Schegloff \& Jefferson, 1974; cf. Sacks, 1963, 1992a,b; Gumperz, 1982; Levinson, 1983; Duranti \& Goodwin, 1992; Goodwin \& Goodwin, 1992) found its way into the study of classroom discourse (see Sinclair \& Coulthard, 1975; M cH oul 1978, M ehan, 1979). So, attention to the genuineness of real-life events and actions became central to the study of classroom discourse.

As a result, even linguistically oriented researchers (e.g. J. Clark, 1969) would question the credibility of research treating the classroom as a laboratory. Consequently, attempts to analyze the discourse of the classroom became more dialogical (see Sinclair \& Coulthard, 1975; M ehan, 1979; A nward, 1983; van Lier, 1988; Gustavsson, 1988, among others). Communication became central to the studies of classroom speech events from both sides of linguistic and anthropological-sociological studies, and it turned out to be common among many researchers to agree that examining classroom discourse is the examination of its communication system (Cazden, 1986: 432).

The popularity of focusing on the communication system (the sequential analysis of speech events) in classrooms actually started early on by presenting communicative models in the classroom, as, for example, the ones proposed by Bellack, et al. (1966), Sinclair and Coulthard (1975), and M ehan (1979). These studies uncovered a three-turn sequence pattern of talk that occurs between teachers and students. A model of Soliciting-Responding-Reacting (SRR or the 'teaching circle') was first proposed by Bellack et al. (1966). This was followed by Sinclair and Coulthard's (1975) account of classroom discourse, with their famous sequence model of Initiation-Response-Feedback (IRF), which, in turn, was also 
followed by Mehan's (1979) proposed model of Initiation-Response-Evaluation (IRE). Sinclair and Coulthard's model, however, has been criticized partly because of its specified hierarchal character of context (Drew \& Heritage, 1992: 13-14), and its linguistically oriented description of actions.

With his model Mehan (1979), however, tries to attend to human nonverbal conduct as well as speech. With a method of analysis that he calls 'constitutive ethnography' (ibid, p. 8), he attempts to capture the overall dynamics of communicative events and discourses in the classroom. Otherwise, a gross image of the sequential pattern of talk glosses over the details of the interactional organizations that actually occur in classrooms.

With the following example, I will demonstrate that if one would like to understand the organization of activity in the classroom, the procedure of learning in its actual environment, or the emergence of a phenomenon in these activities oriented to as a learnable, how significant it is not to miss the interactional details (see also Seedhouse, 2004: 66-67, 2007; cf. Markee \& Kasper, 2004). In the presented sequential trajectory, a teacher elicits a response, and after receiving one from a student, evaluates it:

Excerpt 2a: Kind_to: Tape A $n, C$ level (Simplified)

Participants: Teacher (T ea), Student 9 (St9)

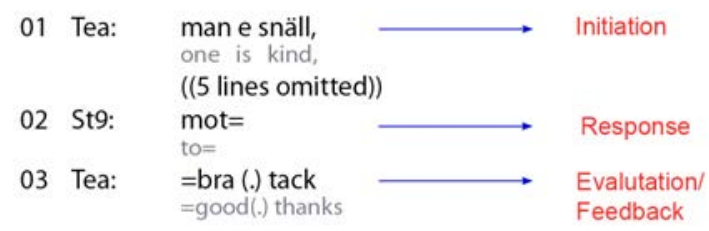

In the excerpt above, the designedly incomplete utterance (line 1; see Koshik, 2002) by the teacher is a prompt to receive a matching preposition (mot, line 2). $W$ hen it is given to her, she positively assesses the response (line 3). These three consecutive actions are the pattern recognizable in many small local instructing/learning projects in teacher-student talks (M ehan, 1979). The three-turn sequence structure is indeed 'a constitutive field of action' in the classroom (Macbeth, 2003: 258), in and through which, moreover, other things may be 
interesting to attend to: The formation or change of the classroom contexts (Seedhouse, 2004), the use of nonverbal acts (see Study 2), the complexity of the interactional work of the participants and the dynamics of face-to-face interaction, the contingency of actions, the expansion of sequences, the change of topic, multiparty talk, among other things.

This exchange of turns may be exploited for other practices. In unfolding talk, the teacher may halt his/her turn before completion for the students' participation, as shown in the example above, or e.g. a choral response by the class may be made relevant (see L erner, 1995). The position of the response might not always be filled by preferred responses, so some inserted turns might be occasioned (see M ondada \& Pekarek Doehler, 2004). The teacher's feedback might also be withheld for pedagogical purposes (Lee, 2007; see also Schegloff, 2007: 224). The evaluation is not necessarily placed always at the end of each set of IRF/E, after each student's response (see also Cazden 2001: 32; see also Zemel \& K oschmann, 2011).

Thus, each interactional position in the three-turn structure may not be constituted by only one turn, but, rather, a longer stretch of talk. The sequence of turns may be expanded by a follow-up action. That is, in the 'instructional sequences' (Mehan 1979: 52) that the response is not obtained, pursuing a response, and further negotiation might be necessary. What is more, this routine pattern is not the only pattern of the interactional sequences in classrooms; there might also be divergence from the routine pattern of interaction ( $M$ ehan, 1979: 103; see M arkee, 2000; Gardner, 2013), and talk is not the only resource used in shaping the sequences of actions. A closer inspection of sequential trajectories of teacher-student talk may show a more detailed dynamism of classroom interaction on the occasion of its occurrence. For example in Excerpt $2 \mathrm{a}$, if one attends to a more detailed exchange of actions, and also to their multimodal productions, one can come up with a somewhat better understanding of the situation and of the organization of order in the interchange: 
Excerpt 2b: Kind_to: Tape A n, C level

Participants: Teacher (T ea), Student 1 (St), Student 2 (St2), ... Student 9 (St9)

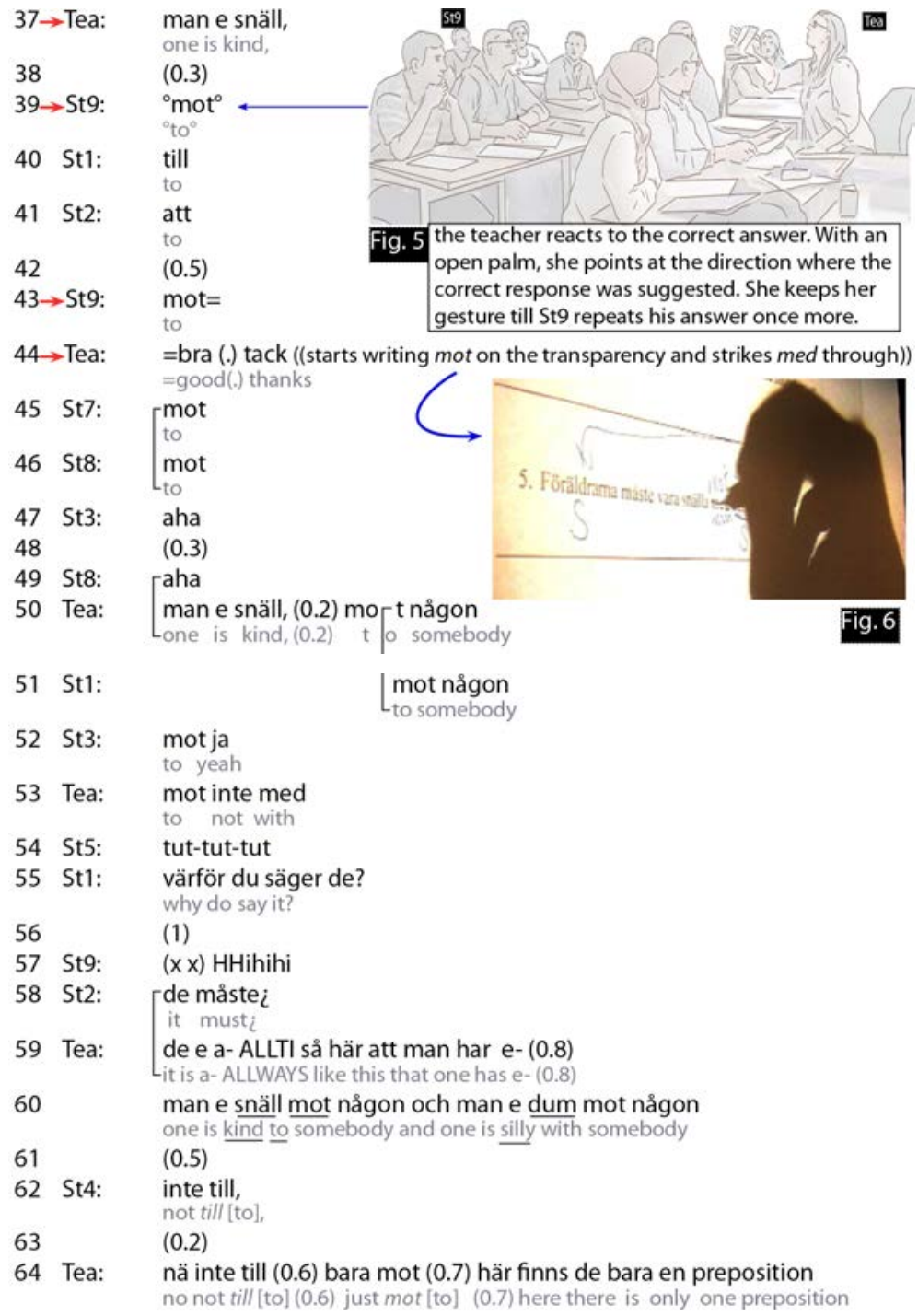

The example is in fact a negotiation over a task in which the students were given a number of sentences on a worksheet and assigned to find mistakes in those sentences. They have worked in groups of two and three and now the teacher asks the students to present their answers out loud to the whole class while the teacher 
uses an overhead projector showing the same sentences on the white screen in front of the class.

What we see in the conversation above is the interactional efforts of the students (not just one) in constructing a correct response to a slot-leaving incomplete utterance asking for a filler, arguably a preposition (line 37; see Koshik, 2002). When the candidate suggestions are given (cf. Lerner, 1996), one answer is picked up as a correct answer by the teacher through a gesture she makes. The teacher, after receiving the first response (line 39), shows that it is a desired response through a visible embodied display. She tilts her upper body to one side, leans forward and faces the way that the answer was produced. She then raises her hand with an open palm and directs it toward St9 (fig. 5), and holds her hand until St9 produces the correct preposition once more (line 43). Then, she positively evaluates it without any delay (line 44).

First of all, the production of the response is not done by one person in one single turn in a dyadic teacher-student talk. Out of the competitive contributions, one of the answers was selected by the teacher and repeated as a correct one. Second, the teacher's embodied action plays a crucial role in the selection of the desired response. Third, with her immediate evaluation the teacher in fact puts an end to the production of more responses. However, the sequence is not yet over. The third-position evaluation, which is in most cases done for the closure of the sequence (Schegloff, 2007: 224) is expanded by 'aha' turns and the repetitions of the answer (lines 45-49), which are typical of these classroom multiparty conversations. At the same time, the teacher finishes up the activity by writing down the correct preposition 'mot' on the worksheet (fig. 6). She reads the incorrect form and at the same time writes down what they (teacher and the students together) achieved as an answer to the question. As she corrects the preposition on the overhead she reads out 'mot inte med' ('to not with', line 53). The corrective writing on the overhead is publicly visible to everybody in the class.

But not even writing the correct response and repeating it for the whole class is the end of the story. A follow up question (line 55), which is actually directed at a student (St1 and St2) and not at the teacher, nevertheless, is treated as a request by 
the teacher for a further explanation (line 59). She regularizes the use of the preposition 'mot' in constructions such as 'snäll mot någon' or 'dum mot någon' (line 60) as a linguistic rule, and highlights its saliency and learnability (see lines 59-64).

As Cazden (2001) also mentions, demonstrations of basic sequential activities in classrooms should take the details of local micro negotiations into account. The initiation, the response and the feedback or evaluation, each has a selection dimension (ibid, 37), and contingency constraints, which are indispensable to human interaction. This is also part of 'the naturalistic study of the everyday life of the classroom' (M acbeth, 2003: 240), which M ehan has al so pointed out.

Even if quantification schemes and paying attention to the frequency of events are useful, what we learn from studying classroom interactivities is that the reality of participants' contributions to the interaction, e.g. in IRF/E sequential pattern, draws attention to many other details. These details highlight the interrelationship of verbal and nonverbal conduct, their effects on shaping context, and the function of language use, bodily actions and the use of artifacts in the social dynamic of communicative events.

The importance of paying attention to details of social activities also shows that what the research study in this field demands is not only ordinary fieldwork in the form of 'participant observation', but also preservation and reexamination of the details of the design of actions, verbal and nonverbal behavior, etc. which can only be captured by other methodological tools than mere observations, for example recording the communicative events by technological devices.

\subsection{Research on Swedish-for-Immigrants (SFI) classes}

From an EM/CA perspective, the amount of research on the inside of SFI, particularly on the organization of interactivities, is relatively slight. There are, however, a number of studies on immigrants' language learning in Sweden, covering different issues ranging from formal linguistic difficulties in language learning (e.g. Bannert, 1984), cognitive linguistic issues (e.g. Håkansson, 1987; Lindberg, 1995) to the problem of literacy (e.g. Elmeroth, 2003) and the issue of 
social categorization, identity, integration, marginalization, policy, power, employment, ethics, etc. (e.g. Boye-Møller, 1973; Opper, 1983; Norberg, 2000; Granberg, 2001; Norman, 2004; Anderson and Osman, 2008; Rosén \& BaggaGupta, 2013; to name a few; for an elaboration on studies on SFI, see also Lindberg \& Sandwall, 2007). There are far more studies on the role of language learning in regard to the inclusion of foreigners in Swedish society from sociopolitical views (e.g. Beijer \& Bolin, 2003) than the reality of language learning as a social practice from the participants' perspective.

From socio-cognitive and socio-cultural perspectives, interaction in SFI has been attended to (e.g. Lindberg \& Skeppstedt, 2000). Lindberg (2003), for example, brings evidence from interactional events inside and outside SFI classrooms to show how important it is to know what language learners and their partners in interaction do and how they do it. She rightly points out that opportunities for learning emerge in social interaction. This interactive engagement, she says (p. 163), helps the learners of a second language to become more aware of their learning and their development. This, in turn, helps them to learn more.

To the best of my knowledge, the only study from a sociological perspective that has studied the organizational order within SFI is Carlson's (2002) work in which she tries to capture the production and reproduction of knowledge within the social processes of activities in SFI. Carlson shows how the educational setting is lodged in an ideological context. Her study is derived from interviews that she made with SFI students and mirrors their practical problems in reality with the process of learning Swedish as a second language. Her study (see also Carlson, 2006) is an examination of how the construction of knowledge is both influenced by different institutional contexts and co-built by students and teachers.

A part from the undeniable significance of research about the general problems of immigration in Sweden and linguistic aspects of learning Swedish, which require many more studies, what seems also to be important about the SFI course is what occurs inside classes from different perspectives, psychologically, socially, culturally, etc. As far as this research project is concerned, there is still plenty of 
room for studies about the organization of SFI classroom situations, the ethnography of education in SFI, the detailed study of communicative skills/strategies/acts inside SFI classrooms, and qualitative research about interactional practices among participants in the SFI course, teachers and students alike. The last-mentioned area is what this research project concentrates on.

As Carlson (2002) also aims at, research on SFI from the inside may shed light on the process of socialization and enculturation of sojourners or new citizens in Sweden. Basically, it shows that language learning, and socialization for that matter, are not merely like acquiring a stock of quantitatively measurable forms. Language competence is not a package to be passed on to the language learners, and 'attributes' of language learners cannot be merely measured in quantity as someone measures the weight of a package ( $c f$. B achman, 1990: 18-31). There is much more into 'learning' and 'showing' those abilities as social skills for interacting and making social actions (see also Lindberg, 2003). The studies presented here are meant to contribute to such a view as well. 


\section{Data and methods}

Studies on social interaction (e.g. Goffman 1956, 1963, 1974, 1981) have proved that the phenomenon of order in interactivities and their systematics require meticulous observation of social situations and description of what really occurs within their participation frameworks (Goffman, 1981; cf. Goodwin \& Goodwin, 1987; C. Goodwin, 2000a, c). As was shown briefly in the introduction, working out the phenomenon of order in social activities from within (Garfinkel, 1967, 1996, 2002: passim) means inquiring into members' methods and perspectives in the organization of social practices and their organizational order in situ and in vivo.

For the purpose of studying interactivities more closely in their details, recording communicative events proves to be a crucial resource. A digitized recording of social events gives an opportunity to examine them, and also to preserve the recordings for further investigations and reexaminations of the data (see Sacks, 1984). Since the focus of this project lies in embodied actions, a video recording is more suitable than mere audio recordings.

I have chosen Swedish-for-Immigrants (SFI) classes as the setting for collecting the empirical data. In the following sections, a brief description of the setting and grounds for this type of data collection will be presented. The multimodal approach to the videos, the pros and cons of such a method of data gathering, and some specifications of the excerpts used for the investigation of learnables will also be presented.

\subsection{Swedish-for-Immigrants (SFI)}

Sweden has welcomed an increasing number of sojourners and immigrants in the recent decades. Since the 1940s and the 1950s when the need and the attraction for manpower resources attracted the first influx of immigrants, Sweden has become a 
community with an urgent need for language training for immigrants (BoyeM øller, 1973). A Swedish teaching course for immigrants was opened to the public for that reason in 1965, and since 1972, SFI has been officially funded by the state to serve as a special course for adult foreigners who learn Swedish as a second language (for an elaborate account of the development of SFI, see Lindberg \& Sandwall, 2007).

The SFI course is offered with the aim of facilitating the new residents' integration into the society and their readiness for the labor market (Skolinspektions rapport [School inspection report], 2011: 6). It is financed by the municipalities and administered by certain schools in almost every city faced with the demands of the new arrivals. The number of students applying for learning Swedish in SFI grows on a yearly basis. The number of participants in SFI courses has soared from about 30,000 in $1994 / 95$ to 52,500 in $2005 / 6^{2}$ and 108,000 in $2012 / 13^{3}$. This, too, shows the necessity for research on this particular setting with its growing social demand.

SFI has four language proficiency levels, A, B, C and D, which correspond to the Common European Framework of Reference for $L$ anguages (CEFR). Course $A$ is consonant with level $A 1-/ A$; course $B$ is congruent with level $A 1 / A 2$; course $C$ corresponds to level $A 2 / A 2+$, and course $D$ is equivalent to level $B 1 / B 1+$. The syllabi and the criteria for instructing, testing and evaluating the students at each level are designed by Skolverket (the Swedish $N$ ational A gency for E ducation).

Skolverket (2012: 8), in its recent booklet about SFI, highlights the ultimate goals for the SFI course as 'the individual development of each student, their understanding of their own learning and their awareness of how language is learned'.

\footnotetext{
${ }^{2}$ The information can be found on the official website of the Swedish $\mathrm{N}$ ational A gency for Education, retrieved on A ugust 4, 2013:

http://www.skolverket.se/statistik-och-utvardering/statistik/utbildning-i-svenska-forinvandrare/beskrivning-av-statistiken/en-tioprocentig-okning-av-antal et-elever-i-sfi-1.40053

${ }^{3}$ The information can be found on the official website of the Swedish $\mathrm{N}$ ational A gency for Education, retrieved on A ugust 4, 2013:

http://www.skolverket.se/statistik-och-utvardering/statistik/utbildning-i-svenska-forinvandrare/beskrivning-av-statistiken/antal et-el ever-i-sfi-fortsatter-att-oka-1.203979
} 
In essence, the objectives for SFI (ibid) are defined in this way: The students are considered successful in communicating in Swedish if they learn each language skill (listening, reading, writing and speaking) to the extent that they know what kind of forms they can be used in different communicative situations and in which manner (how). It is also expected that the students, at the end of the course, should be able to individually continue their own language development, i.e. to become independent language learners (perhaps learning on their own, or from others in other settings than language classes). To reach these objectives, there are course plans and detailed curricula for each level of SFI.

This research project will not attend in any critical way to the details of the objectives of SFI and how they are carried out in the classroom, but nonetheless, by analyzing some actual classroom data, it will show part of the complexity of interactivities and the reality of teaching and learning in face-to-face interaction in this setting.

\subsection{The empirical data}

The data gathered consists of around 50 hours of video-recordings of classroom interactivities, augmented by direct observations that I have made personally as a participant in Swedish-for-immigrants-classes (SFI). The video-recordings are from the sessions at the end of $\mathrm{C}$ level classes and also from the beginning lectures of D level classes of SFI. All participants are adult with different linguistic backgrounds. The participants in each class are not homogeneous when it comes to their level of proficiency in the Swedish language.

Even though recorded in different SFI classes, the empirical data does not necessarily represent SFI as an institution. The excerpts used here are idiosyncratic to their occasions even though the practices involved in the interactivities may be familiarly findable in many similar or dissimilar settings and events; nonetheless, for the purpose of this study, I do not claim any representational status for the corpus of data toward either SFI or second language learning discourse in general. A part from that, the practices of the members in the setting, notwithstanding their uniqueness in their acts for the practical purpose of that event, are part of 
witnessable patterns of doing things in social situations, which can be found anywhere (see Garfinkel, 1996: 10). Accordingly, some patterns are presented based on the findings of the investigations which may be informative, instructable and, also, generalizable.

\subsubsection{Multimodality and video-recording}

Multimodality may be defined as the use of different semiotic resources such as talk, the body and maybe artifacts in the design of 'meaning, knowledge and action' (C. Goodwin, 2002: 33, cf. K ress \& van Leeuwen, 2001: 20; J ewitt, 2011: 1). In social activities involving human participants, the phenomenon of participation would be inadequately described if the range of semiotic resources used by the participants was not taken into consideration (C. Goodwin, 2000a, C; see also Stivers \& Sidnell, 2005; M urphy, 2012; B roth \& M ondada, 2013). That is why as part of the analytic observation of the procedures in and through which opportunities for the emergence of learnables are shaped, I shall attend to the variety of modalities and what actually occurs in the sequence of actions (see also Sacks, 1984: 25).

The observation of semiotic resources in detail as actually occurring in natural events requires methodological tools to capture them in their context of occurrences. Direct observation, however meticulous, may lose some small phenomena of order that may be crucial to the construction of the organization of order in the design of actions, sequences, and the whole activity (see also M ondada 2013).

The smallness of the phenomena does not mean that this study is about small objects in opposition to larger objects. The resources that this study is going to investigate are necessary ones, the building blocks of the procedure out of which learnables are shaped and fashioned. I do not, thus, talk about micro- in opposition to macro-size of data but the normal and ordinary size of data (see Schegloff, 1988: 100) that are used ipso facto in the organization of interactivities in the studied setting. 
Even though direct observation and interviews are standard methods of data collection when it comes to the analysis of the organization of members' practices (e.g. following Garfinkel, 1967, 1996, 2002), meticulous analysis requires reexaminable data exhibiting the detail of such an organization.

Video-recording contributes to observation as a reexaminable method of theorizing about the subject matter (Sacks, 1984: 26). With actions recorded on tapes or electronic storage devices, we will access the conduct that might otherwise have remained unrecognized in other ways both to analysts and to participants (see Peräkylä, 2006: 82; Luff, Heath \& Pitsch, 2011: 215) especially if the participants were asked in retrospect what they did and how they did it.

Even though video-recordings are used in this study as the main data source, they are not the only source of data. They are complemented by participantobservation conducted by myself. This combination could be particularly useful in cases where extra information is necessary for understanding the recordings, and the context of the activity. Such information may be relevant but not accessible in the tapes, e.g. accounting for the larger activity that the studied sequence of events is lodged in, the previous unrecorded activities, or things happening out of the camera shot that might be relevant to the organization of the studied activity. This extra information is given whenever a case is analyzed in the empirical studies ( $c f$. Studies 1-3).

\subsubsection{Video-recordings; prospects and consequences}

One of the earliest studies of the internal life of classrooms is M ehan's 1979 Learning lessons. In his book he explains (1979: 72) that conventional field studies in the capacity of a 'participant-observer', even though significant, bear some difficulties. One of the shortcomings of a mere field observation is the danger of relying on the 'anecdotal' quality of the field notes, the 'tabular or summary form' (ibid) of the observation, without having retrievable and reexaminable data. He, therefore, concludes that 'it is impossible to entertain alternative interpretations of the same materials' (Mehan, 1979: 15). This problem was also highlighted by Sacks (1992a: 28) when he called for 'building an observational study' that can use 
sociological data as objects of study in a way that the material and the claims can be rechecked, or tested again.

Tape-recording was the solution that Sacks and his colleagues came up when conducting research on telephone conversations to preserve the collected data that could be checked, typed out, and repeatedly worked on (Sacks, 1992a: 622). Attending to both verbal and nonverbal conduct in social activities, however, requires an observational study that can use images as well as sounds as its research objects. In the history of research on human conduct, B ateson and $M$ ead (1942) already showed the importance of pictures in ethnographic work when they gave a visible account of B alinese everyday behavior.

However, video cameras with pioneering studies of researchers such as Birdwhistell, Scheflen, Condon \& Ogston, Kendon, C. Goodwin, M.H. Goodwin, $H$ eath, among others, have brought a change in the method of collecting data and studying phenomena especially in human social conduct. Videos are shown to be excellent sources for preserving data for the study of everyday social activities.

Even though photo-cameras and audiotape-recorders are still part of the equipment that field researchers use, video-recording is simply now the only way to collect retrievable data when it comes to a detailed study of interactivities, especially when examining nonverbal behavior in multimodal and multiparty interactional settings. There is no better way to sketch the multimodal character of social practices than using excerpts from videos to display the witnessable evidences of the members' methods while forming an action (see e.g. C. Goodwin, 2000b,c; 2003; 2007a; 2013; see also Heath, Luff \& Svensson, 2007).

Using video as a methodological tool, however, is not without its problems. A s M ondada (2006) argues, the ways that videos are produced are usually based on biased choices, and, therefore, they simply do not allow the researchers to transparently see the entire social field vis-à-vis the participant-observation 'out there' in the setting. Moreover, whereas ethnographic work and participantobservation techniques in data gathering may be intrusive or nonintrusive (Duranti, 1997: 99), the recording technique is usually accused of being intrusive (ibid: 118). That is, the presence of cameras in the field might be disturbing, if the participants 
feel uncomfortable before the recording devices, and/or the setting does not keep its natural ness intact in their presence.

The argument for the presence of a camera or any other artifacts in the studied setting, nonetheless, can also be made for the presence of the ethnographer or any participant-observer in the field, no matter how much they try to behave passively in the setting and try not to interfere with its organization.

There are also some ways to attenuate the intrusiveness of the camera and minimize the risk of compromising the naturalness of the setting. For instance, camera devices can be in different sizes and their size may affect their physical intrusiveness in the setting. The position of the camera in the setting or the presence of the analyst behind the camera can make a difference as well (see Study 1 where the camera becomes the topic of an inquiry). In the process of gathering data for this research project, in some situations, for instance, where the participants showed some uneasiness with regard to my presence, I set the camera on a stable tripod in a corner at some distance from the gathering and left it to record the event. In most cases, however, as I was participating in the course of language learning activities, I was accepted as a member, a participant-observer, and my camera and I were considered part of the setting after a while. Although the presence of the camera might bring drastic changes in the conduct of the participants that one may be wary of, fortunately, I observed none.

The use of cameras has some undeniable benefits that outweigh its possible negative influence. After recording, by using special computer programs, one can transcribe talk and follow the sounds and nonverbal acts at the same time. One can visually bring before their readers, through words and pictures, the complex forms of social interaction. To scrutinize a setting, the details of the conduct and the use of artifacts and their effects on the organization of that setup, the participation and interaction, it is rewarding to record the setting and to have the ability to use slow motion, or to rewind or zoom the shots, etc. (Luff et al., 2011: 215; see also M ondada 2013). Paying attention to the coordination of conduct between the speaker and the hearer at the same time (C. Goodwin, 1981: 45), and to the details 
of the conduct, like the participants' embodied behavior or gaze, would not be possible using mere observation.

In gathering data, I simply traded off the possible influence of the camera on the field for the benefit of capturing more precise data on the tapes. The social behavior including talk, bodily actions and the use of other available resources would be missed relying only on field notes, and now are preserved for repeated observation and reexamination.

The importance of video-recording, as shown in Excerpt 1 in the introduction and Excerpt 2 in section 2.4, may be argued with regard to the following example as well. Two beginner's students are engaged in a conversation talking about how many siblings they have. The two have no common language but some Swedish that they have learned so far in the Swedish class and elsewhere. What they exchange is far from grammatically correct utterances.

B elow is an audio transcript of the conversation which shows how much might be lost if an analyst would not capture the details of embodied practices:

Excerpt 3a: Twin. A (C)

Participants: Student A (A), Student B (B)

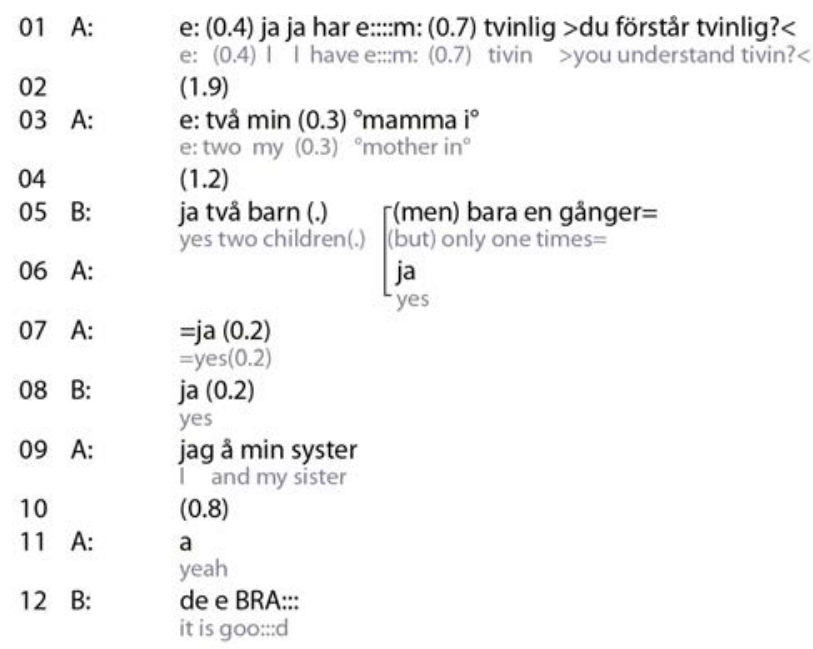

Here, student A is telling student B that she has a twin sister. Without any doubt, one can easily observe that from the audio transcript, one cannot have a full 
understanding of the use of diverse semiotic resources by the participants. For instance, the seeming silence in line 2 after the question that is posed by $A$ is not actually a pause without participants carrying out any communicative acts. In actual talk, the question is not left unanswered, but it gets a reply from $B$ through a head shake, which is not accessible on audio and hence not transcribed.

The word explanation that A initiates in line 3 in response to the head shake is not just an incomplete meaningless utterance but is completed by A's hand gesture pointing to her own abdomen. This 'composite utterance' (Enfield, Kita and de Ruiter, 2007) is made meaningfully complete by the combination of talk and gesture.

The multimodal transcription below shows how missing pieces of information may be crucial to the understanding of the methods of communication that the two students use in their talk:

Excerpt 3b: Twin: Tape A $n, C$ level

Participants: Student A (A), Student B (B)

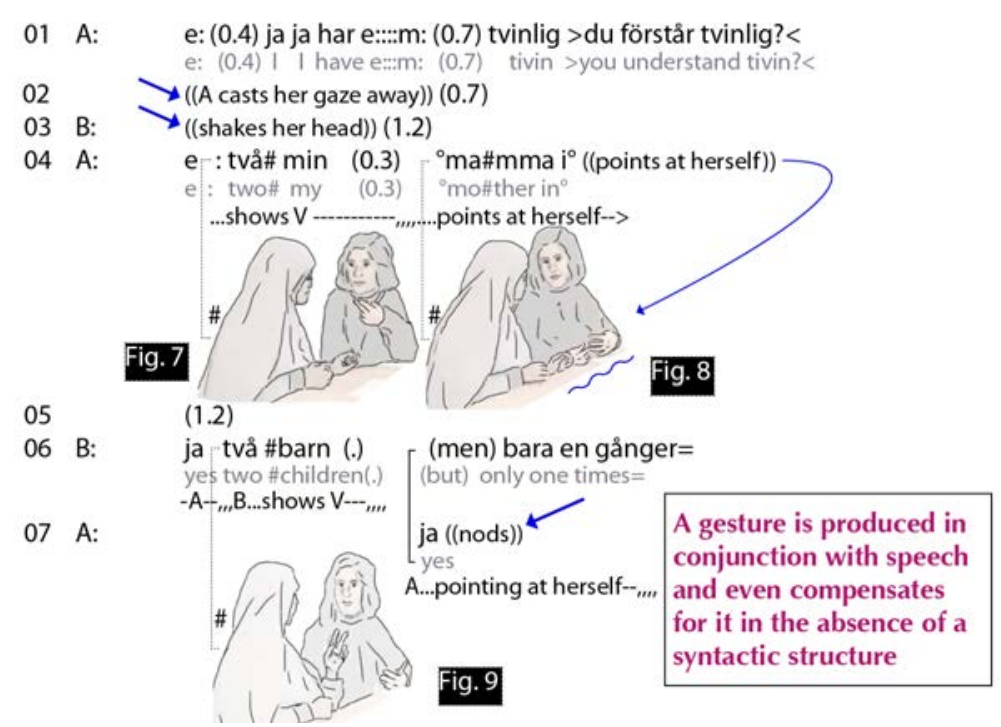




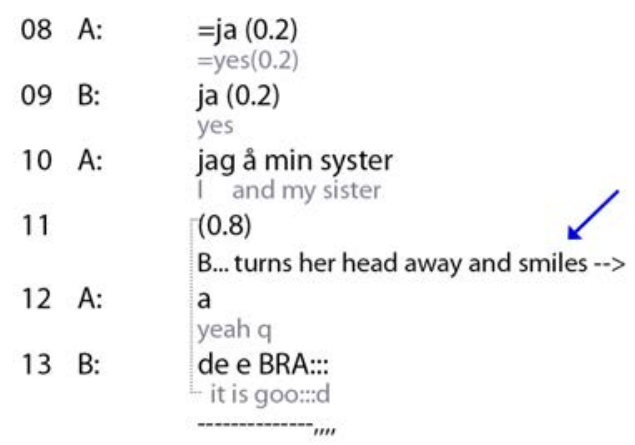

A udio- and video-recording can be the only way to reexamine the details of communication when investigating the actual architecture of interaction in its moment-by-moment unfolding. Through the lenses of recording cameras, one may capture the multimodal nature of human communication. Body and head movements, hand gestures (e.g. here, showing number with fingers, pointing at the abdomen, figs. 7-9), turning the gaze, torso, etc. would be missed if they were not recorded on videos. What is not seen through the lenses of the cameras, if crucial for understanding the event, may be compensated for by the field notes. However, the precision of access to the preserved data simply outw eighs other methods when it comes to the details of conduct, and the benefit of reexamining them.

\subsubsection{Excerpts and transcriptions}

The video-recordings which were made during my observation of the field over the span of one and half years, are taken from different classroom interactivities, ranging from informal, non-pedagogical and unplanned activities to formal, pedagogical and planned ones. The phenomenon of order in the organization of learnables became the topic of study only after a close observation of the activities and after numerous times watching the 50 hours of videos comprising the data corpus of the study.

The data used include sequences of interaction only between teachers and students in different sequence types such as word-search or vocabulary inquiry, word meaning explanation, providing grammar instruction, formulation and reformulation practices. 
In selecting topics for the empirical studies (Study 1-3), I sifted through large amounts of data in order to look for significant and recurrent practices. Having found what seemed to be phenomena typical for some interactivities in the data, I tried to build a collection of occurrences of the phenomena in question. The studies are built on such collections. The collected cases used for this study, however, are not the representative of the whole data corpus, but rather illustrative examples for embodied achievement of learnables in teacher-student talk-in-interaction.

\subsubsection{Transcription conventions}

The conventions used in the transcriptions in this research project are notations used for verbal and nonverbal conduct based on J effersonian tradition augmented by some multimodal transcript notations (see e.g. Goodwin, 1979, 1981; A tkinson \& Heritage, 1984; Mondada, 2007b). Nonverbal conduct is described either in parentheses on the same line with the turn at talk, or is set on a separate line with the specific notations. I also use pictures and series of drawings to tangibly illustrate actions. The positions of pictures are shown in the turns of talk with dotted brackets. Table 1 presents the notations.

Table 1- Transcription conventions

\begin{tabular}{|l|l|}
\hline [ & left square bracket: a point of overlap onset \\
\hline$(0.5)$ & equal signs: 1. two lines are connected 2 . one turn is latched by another \\
\hline$()$. & a dot in parentheses: a micro-pause (usually less than 0.2 seconds) \\
\hline$\cdot$ & period: falling intonation \\
\hline$?$ & question mark: rising intonation \\
\hline, & comma: continuing intonation \\
\hline$i$ & inverted question mark: a rise stronger than a comma but weaker than question \\
\hline
\end{tabular}




\begin{tabular}{|c|c|}
\hline$:::$ & colons: prolongation or stretching of the sound \\
\hline- & hyphen: after a word or part of a word indicates a cut-off or self-interruption \\
\hline Word & underlining: stress or emphasis by increased loudness or higher pitch \\
\hline WOR & all capital letters: much louder than the surrounding words \\
\hline$\circ \circ$ & degree signs: the word is markedly quiet or soft \\
\hline$\uparrow \downarrow$ & up and down arrows: sharper rise or fall in pitch \\
\hline$><$ & more than, less than: with a jump-start, said in rush quickly \\
\hline$<>$ & less than, more than: is markedly slowed or drawn out \\
\hline Hhh & out-breath: laughter in voice \\
\hline.$h h h$ & in-breath \\
\hline$(())$ & double parentheses: transcriber's comments \\
\hline (word) & utterance in parentheses: transcription is not certain \\
\hline ( ) & empty parenthesis: something is being said, but no hearing can be achieved \\
\hline$\ldots$. & described gesture's preparation \\
\hline$-\cdots$ & gesture's preparation apex is reached and maintained \\
\hline , & gesture's retraction \\
\hline$-\cdots>$ & gesture or action described continues across subsequent lines \\
\hline$-\cdots>>$ & gesture or action described continues until and after excerpt's end \\
\hline \# & hashtag: the position of an image within a turn at talk \\
\hline $\begin{array}{l}\vdots \\
\vdots\end{array}$ & $\begin{array}{l}\text { dotted square bracket: aligning the position of an image with its nonverbal } \\
\text { description and a turn at talk }\end{array}$ \\
\hline
\end{tabular}




\section{Analytic approaches}

In what follows, I will briefly present the analytical framework of the study. The dialogical and praxeological principles of the current research project will be outlined and some principle concepts will be explicated. A more elaborate account of this line of theoretical development will be presented in Study 4 as well.

\subsection{Analytic framework}

Doing multimodal interactional analysis of the design and exchange of embodied actions, this study adopts a method of analysis which is based on dialogical (contextual and interactional, see Linell, 1998, 2009) and praxeological framew orks of research (ethnomethodological conversation analysis, see Garfinkel, 1967, 1996, 2002; Garfinkel \& Sacks, 1970/1986; Sacks et al., 1974; Sacks, 1992a,b).

A study of the interactional life of classroom activities requires attention to the organization of the activities, the social behavior of the participants, and the coordination of behaviors in the accomplishment of the activities.

Second language students, too, engage in language use within social interaction as the locus of socialization and learning ( $c f .0$ chs, 1982; Ochs \& Schieffelin, 1979; Schieffelin \& Ochs, 1986; see also Schegloff, 1987 for describing talk-ininteraction as 'the primordial locus of sociality'). The account of how students are involved in language learning practices, creating opportunities for learning and orienting to learnables, should take into consideration not only the issue of the spoken discourse in the interactivities but also the interdependence of communicative acts with each other, and with the activities they are lodged in (Linell, 1998; cf. Firth and Wagner, 1997). That is, in examining social situations involving activities of language teaching and learning, the context as a 'frame' the situation as an occasion - embodying resources that shape any focal event (Goffman, 1974; see also, Goodwin \& Duranti, 1992) should be taken into account. These contexts and resources are not defined by analysts, but they are used by the participants in the activity, and are shaped or made relevant by them in 
the organization of the setting (see also B ateson, 1972). Within this frame, it is not the analyst's perspective that is described, but rather the participants' perspectives and methods (see Garfinkel, 1967; Garfinkel \& Sacks, 1970/1986). These methods are the points of departure for the description and the analysis of an event.

\subsection{Praxeology of interactivities as dialogic events}

A detailed account of the theoretical framework is going to be presented in Study 4. Here it may suffice to mention some preliminary theoretical issues as a frame for introducing the method of analysis adopted in the studies.

Interactivity may be defined as an interactional activity, that is, interaction through available semiotic resources by mutually co-present people to accomplish a course of actions ( $c f$. Linell, 1998: 10). A formal analysis of interactivities, thus, requires attention not only to each individual action but also to the coordination and cooperation in building co-actions and comprehensive activities as basic to the interactivities ( $c f$. Linell, 1998: 13; see also Goodwin, 2013). So, interactivities are constructed by a methodically built ensemble of cooperative actions that are organized orderly. This order is at all points of their occurrences (see Sacks, 1984: 22). We are not, therefore, talking about only the structure of activities, like the structure of language activity, as an abstract theme, but rather the interrelation of praxis and that structure (see Linell, 1998: 33). That is, the focus is on the language practices (languaging, Becker, 1991; Linell, 1998: 36) and other embodied practices to shape interactivities involving language teaching and learning.

What is being studied is not the distinct forms separated from functions, or content from structure, etc., but analyzing them all in 'reflexive relations of coconstruction' of the activities (M acbeth, 2014). This is also the tenet of Garfinkel's ethnomethodology to which we will now turn.

\subsubsection{Ethnomethodology (EM)}

EM is a sociological/phenomenological framework of analyzing the phenomenon of order in commonplace social activities through attending to embodied social 
practices in the perception and the production of witnessable and recognizable social phenomena (Garfinkel, 1967, 2002: passim; see also Rawls, 2002: 4). It premises that the 'objectivity of accounts' of an activity depends on 'the socially organized occasions of their use' (Garfinkel, 1967: 3). What is being studied then is 'the rational accountability of practical actions as an ongoing, practical accomplishment' (ibid, p. 4).

Developed by Harold Garfinkel in the span of seven decades, since the late 1930s (Rawls, 2002: 4), EM has become the extension of some philosophical and sociological investigations originating in the works of Husserl, Heidegger, Schutz, and Merleau Ponty, and also respecifying Parsons' theory of social action (Heritage 1984; see also Garfinkel, 1996). Garfinkel (e.g. 1967) also shows how Wittgenstein's way of describing language is actually practiced on everyday occasions. He shows us how understanding between two people is 'accorded with the relationship of their interaction', 'as an intersubjectively used grammatical scheme for analyzing each other's talk' (Garfinkel, 1967: 30-31). This is the way people understand each other, and this is the way, he suggests (ibid, p. 31), that the analyst should 'use the common sense knowledge of the society in exactly the ways that members use it', or, in other words, the analyst should 'assign exclusive priority to the study of methods and concerted actions and methods of common understanding [...] in recognizing, using, and producing the orderly ways of cultural settings from 'within' those settings' (ibid). Therefore, orderliness of any activity and its situated accomplishment by the participants of that activity is the analyst's research topic.

Following Garfinkel's studying phenomenon of order in different settings in his early works, such as the orderliness in the organization of clinical records, or the work of a jury, or the managing methods of a transsexual for achieving her sexual status as normal (Garfinkel, 1967: 137), EM has been applied to a variety of mundane or institutional settings (e.g. EM studies on the scientific work of astronomers discovering the optical pulsar in Garfinkel, Lynch \& Livingston, 1981; or laboratory work in Lynch, 1985). What grew out of the ethnomethodological program, which was applied especially to social interactions, 
was a domain suggested by Sacks (1984a: 21) as 'ethnomethodology/conversation analysis'.

\subsubsection{Conversation analysis $(\mathrm{CA})$}

Harvey Sacks founded CA with the collaboration of Emanuel Schegloff and Gail Jefferson (Heritage, 1984: 233). Inspired by Sacks' lectures (held in 1964-1972, published 1992a,b), which were first circulated in a mimeographed version, CA has risen to become a research program of its own, growing from finding the systematics of the organization of conversations on the phone (Schegloff, 1968; Schegloff \& Sacks, 1973; Sacks et al., 1974; Schegloff, Jefferson \& Sacks, 1977) to studying talk-in-interaction in diverse social settings (see e.g. Psathas, 1979), mundane dinner conversations as well as institutional work places (see e.g. Drew \& Heritage, 1992; Heath et al., 2007; Heath \& Luff, 2007; B roth, 2008; Cekaite \& Björk-Willén, 2012; Jansson, \& Plejert, 2014; Plejert, Jansson \& Y azdanpanah, 2014).

Sacks et al. (1974; see also Schegloff, 1968, 1979; Schegloff \& Sacks, 1973; Schegloff et al., 1977) uncovered a robust relationship between language structure and interactional practices. The CA studies of turn-taking, conditional relevance of turns (as a turn is heard or seen as relevant to the prior one, and its absence may be treated as missing), preference in the design of turns, repair in interaction, etc. lead to define such practices as the building blocks of the architecture of intersubjectivity in human social interactivities (Heritage, 1984).

Within this realm of research, very soon embodied actions (gaze, gesture, posture, etc.) were spotlighted as constitutive of the underlying machinery of talkin-interaction (see C. Goodwin, 1979, 1981; M. H. Goodwin, 1980). The systematic design of talk proposed by Sacks and his colleagues actually maps onto the exchange of other semiotic resources as well. The results of the investigations on the use of non-verbal conduct in interaction have also shown the systematic orderliness in the co-participation in interaction, the speakership and the recipientship (see e.g. C. Goodwin, 1979; M. H. Goodwin, 1980; Heath 1984). Examining the uses of gaze, gesture, and the movement of different parts of bodies 
in conversation (see e.g. Kendon, 1977, 1990, 2004; C. Goodwin, 1981, 1995, 2007a; Goodwin, Goodwin \& Olsher, 2002; Enfield et al., 2007; M ondada, 2007a; B roth \& M ondada, 2013; Deppermann, 2013; Streeck, 2013) have shown us that not only the use of talk, but also the use of the body and even the material world are organized through systematic interactive practices (see al so C. Goodwin, 1995, 2003, 2007a, 2013). These interactive practices, as Garfinkel (1967, 2002) describes, encompass endogenously produced embodied actions. Based on EM/CA and multimodal descriptions of actions in interactivities, there exist some principal concepts that will be briefly discussed below.

\subsubsection{Notes on some principal concepts in dialogical and praxeological methodology}

From the analytic perspective posed here, when the focus of attention is on the phenomenon of endogenous order, every detail of the dynamics of the interactional system must potentially be taken into account. M ethodologically speaking, this is consistent with the emic perspective (see Pike, 1954: chapter 2; see also Garfinkel \& Sacks, 1970/1986; Sacks, 1984) as a way to closely inspect members' methods in the realization of that order from within the activity (an 'endogenous' perspective). That is, the analyst investigates what procedural practices are adopted by the participants in the interactivities for action-formation, mutual understanding, progression of the activity, and organization of its coherence. Therefore, what is significant in this research study is 'interactivity' (co-actions, interactional sequences), and 'action' lying at its basis, as the units of analysis.

As will be detailed later on, the sense and function of an action is decidedly agreed upon in interaction, in the sequential organization of any social activity with regard to the 'just-this-here-and-now' principle considering social phenomena as lived and experienced and not as 'signed objects' (Arminen, 2008: 175; see Garfinkel, 1967, 2002: passim; see also Husserl, 1900-1/2001; Heidegger, 1967; Schutz, 1932/1967). From a conversation analytic point of view, the fundament of this situated social activity is the sequence of actions, or their 'sequencing' 
(Schegloff, 1968, 2007) which are formed by turn-taking (Sacks et al., 1974). The units of turns are called 'turn constructional units' (TCUs).

Each turn can be made up of one or several TCUs. Turns consist in any publicly shared action that can be used by others as a resource to respond to. So, turns, in length, can range from a cry (or a minimally produced sound or other communicative act) to several utterances, when shaping a lengthy turn. New turns can start to be produced when the prior turn is observably closing. A new turn may be produced in overlap with the previous one with the recognition of the end of a turn (J efferson, 1973), or when the turn transition relevance place (TRP) is projected or may be predicted (Schegloff, 1984).

In any spate of talk, if something is misheard, misunderstood or needs remedy in its production, there are remedial actions to be made for the correction of what goes wrong, and that is called repair (Schegloff et al., 1977). Repair can be initiated by the speakers themselves or by others (self- vs. other-initiation). They can also be performed by the speakers themselves or by others (self- vs. otherrepair) (see also Plejert, 2004; K urhila, 2006).

There is another ubiquitous practice in social interaction and that is the practice of 'preference'. In principle, there is a preference for some actions which are frequently reported as 'preferred' practices in interaction, such as the preference for self-correction or self-repair in ordinary conversations which are preferred to other-repair (Schegloff et al., 1977), the preference for social alignment in talk (Pomerantz, 1984), the preference for the progressivity of interaction (Stivers \& Robinson, 2006), etc.

Successive actions in conversation, if produced, heard, and treated in response to each other (e.g. one responsive to the prior one), are often considered as pairs. These paired actions (Sacks, 1992a: 678) are also called adjacency pairs (Schegloff \& Sacks, 1973). They are heard as connected, because in the absence of one, it would be heard or treated as missing. This is called the relevancy rule (Schegloff, 2007: 19) whereby, in reciprocation, a second positioned action is usually heard and treated as the responsive understanding of, and conditionally relevant to, the first-positioned one. 
The relevant actions are, however, not always paired actions. For example, they can be sequentially organized in three consecutive actions (Linell, 2009: 183; see also classroom triadic sequences reported by Bellack et al., 1966; Sinclair \& Coulthard, 1975). These minimal communicative sequences can shape a chain of actions, which are centered around a practical purpose to be accomplished. This goal-oriented course of action in one or several sequences with varying sizes is called a '(local) communicative project' (Linell, 1998, 2009: 178; see also H. Clark, 1996).

People involved in any communicative project are part of at least one participation framework (C. Goodwin, 1981; Goffman, 1981) in which their copresence and co-actions are organized and made relevant (see C. Goodwin, 1981: 98, footnote). This framework is not only a participants' collaborative framework of orientation toward an activity (e.g. a mutual engagement with, or disengagement from an activity; see also M. H. Goodwin, 1980), but it is al so a sustained 'relevant framework for the organization of the participants toward each other' (C. Goodwin, 1981: 108; see also C. Goodwin, 2007b). With a broader definition, a participation framework also involves the participants themselves along with whatever is made relevant or used in the material surround by the participants in interaction as constitutive of actions and components of the activity in hand ( $C$. Goodwin, 2000c: 72).

Participants, therefore, make use not only of verbal resources but also a range of other semiotic resources, which 'are juxtaposed in a way that enables them to mutually elaborate each other'. These 'different kinds of sign phenomena instantiated in diverse media' are called semiotic fields (C. Goodwin, 2000a: 1490). The orientation to, and the relevance of a semiotic field in a participation framework of a communicative project are coordinated in the contextual configuration of the activity in which 'the action of the moment' is built ( $C$. Goodwin, 2013: 11). Every speaker, and also the recipient, is vigilant to these contextualization cues (Gumperz, 1982) to interpret the context (what happens, what exists, and what matters) and to produce an apt next action (cf. M oerman \& Sacks, 1971/1988). 
Members of a setting, an activity or a particular social interaction combine different semiotic fields, shape and modify together the contextual configuration of any moment in interaction. They share what they know and what they do not know. They co-build communicative 'territories of knowledge' (Heritage, 2012: 32 ) in which they can reach a common understanding as to agreeing upon the sense and function of each action (see also Garfinkel \& Sacks, 1970/1986). This occurs in each step of the sequential organization of the activity, as a go-ahead to continue the course of action. They, moreover, link locally situated practices to the community of knowledge and practice (Schutz, 1975: 72; Wenger, 1998). Therefore, they co-construct what may be called an 'epistemic ecology' (Goodwin, 2013: 21) in which participants organize not only the activity, but 'the ways of knowing', and 'how the world is known and operated on in a relevant fashion by a particular community' (ibid.).

Members in social activities recurrently show their competence in the accomplishment of organizing and reorganizing the activities, and settings. In and through this accomplishment, they display their knowing how to accomplish courses of actions. Therefore, this membership does not refer just to the participants but to their practical methods and competence, i.e. the display of knowing, the skill of operation, the mastery of using language in 'assessing, producing, recognizing, insuring, and enforcing consistency, coherence, effectiveness, efficiency, planfulness, and other rational properties of individual and concerted actions' (Garfinkel \& Sacks, 1970/1986: 163). The display of these practical methods in language learning activities is done through local communicative projects (Linell, 2009) that may be called instructing/learning projects.

In sum, this study, to put it briefly, explores members' methods orienting to learnables in Swedish as a second language classrooms. That is, participants in language learning situations are engaged in the objective production of competency (its accomplishment) in local instructing/learning projects. The aim is to show how they mobilize different semiotic fields and co-construct contextual 
configurations in a moment-by-moment fashion to produce a teaching or a learning opportunity in interaction and accomplish learnables. 


\section{Summary of the studies}

This chapter contains a brief overview of the studies that form part of this research project, Studies 1-4. These are separate studies examining the accomplishment of learnables. Study 1 deals with a variety of sources in which the learnables originate. In study 2 the embodied accomplishment of learnables in grammar teaching on a worksheet is demonstrated. Study 3 is about teachers' use of matching gestures as the visible display of action in and through which learnables are offered to the students in various sequence types. Study 4 is a theoretical investigation of learnables from a phenomenological/sociological perspective.

\subsection{Study 1: Emergent learnables in second language classroom interaction $^{4}$}

Study 1 is about the details of the endogenous production of learnables in subordinate activities (see Goffman, 1963: 44), activities which are sustained only momentarily in the course of a main and dominant activity. A $n$ example of such a subordinate activity would be a vocabulary inquiry in the midst of a task in a classroom. Three sequences of such activities are multimodally transcribed and analyzed in detail. The sequences, which are all initiated by the students attending to the context at hand, appear to be side activities (i.e. side sequences, see J efferson, 1972) embedded in the main classroom activity. The topicalized object of inquiry becomes the business of interchange discontinuing the main activity ( $c f$. J efferson, 1987). What is offered in these sequences, for instance a gloss for a material object or an explanation for a word or a gesture, is an opportunity of learning that presents those objects as learnables which were not planned beforehand and emerge only in and through interactivities.

The first sequence shows how a question posed by a teacher turns out to contain a word, which is unknown at least to one of the students who displays his

\footnotetext{
${ }^{4}$ In collaboration with $M$ athias Broth, Department of Culture and Communication, Linköping U niversity.
} 
non-understanding via a question. The word is collaboratively and cooperatively explained by the students as well as the teacher. It is done through a side sequence; the teacher, thereafter, returns to the previous activity.

In the second sequence, a student attending to the physical surrounds topicalizes the camera and the cameraman in the classroom and tries to ask a question about them. The communicative project (Linell, 1998, 2009) takes a long stretch of talk in which not only the teacher but other students also help to resolve the problem of what the first student was actually asking. Different words such as 'camera' and the term 'photographer' emerge in the trajectory of conversation as an answer to his question. The word sought in this sequence is also replied to in a collaborative interactional manner.

The third sequence begins when a student picks up an air-quote gesture in the teacher's talk and problematizes it in interaction with another student. The airquote gesture is exhibited as an unknown object and its sense and function are revealed through interaction with the teacher.

Through these sequences, it is shown how something is interactively established as relevant and developed to become a shared pedagogical focus. In the context of a Swedish as a second language classroom, a learnable, then, may originate not only in the use of an unknown Swedish word whose meaning is then asked for (which amounts to a verbal source for a learnable), but also in an unknown name for an object (a material source for a learnable) or an unknown meaning of a gesture (a gestural source for a learnable). It is shown that within the procedure of interactivities a communicative project turns into something, which may be called an emergent learning project. This project may be quite different from, and in addition to, the teacher's pedagogical agenda in the classroom.

\subsection{Study 2: Finger dialogue. The embodied accomplishment of learnables in instructing grammar on a worksheet}

Study 2 demonstrates how grammatical learnables on a worksheet become foregrounded, identified, and formulated in interaction between a teacher and a student. Through embodied and endogenous practices in a grammar instruction on 
worksheets in teaching Swedish as a second language, it is demonstrated how an 'awareness' to produce a 'grammatically correct' linguistic construct is coachieved by the teacher and the student locally and interactively.

In two sequences of teaching grammar, the study shows how the use of pointing gestures serves the purpose of drawing the attention to the words on the paper which is a crucial practice in bringing learnables forward as mutually oriented foci of pedagogy. In the procedure of instruction, the teachers and students go through an interactive scaffolding in which every step is made through coordinated and co-operative actions (see Goodwin, 2013), constant negotiation of mutual understanding to see and understand the problem resolved and use it as a resource for approaching the next problem. Teaching abstract grammar requires some concrete referents on the surface of the worksheet which are mutually attended to, pointed to and talked about.

The study shows how the use of different resources in interaction does not only facilitate the performance of the learner but also helps the sense-making and understanding of the target grammatical construct. Foregrounding and accounting for the learnables on the grammar worksheet is realized through practices resulting in the creation of an instructed vision (cf. Goodwin, 1994), a special way of seeing and knowing an object of learning. Grammatical learnables are shown to be the procedural outcome of hands-on practices as mutually achieved embodied accomplishments.

\subsection{Study 3: Matching gestures - Teachers' repetitions of the students' gestures in second language learning classrooms}

Study 3 deals with how the embodied accomplishment of learnables is highlighted through matching gestures. In the interactivities studied here, the teacher repeats the students' embodied actions and in doing so produces a gesture matching that of the student.

The study is based on a collection of cases of different sequence types involving word explanation, vocabulary inquiry and correction sequences. In all of these activities, a matching gesture is used first and foremost for a display of 
recipiency (Heath, 1984), but also for showing understanding, and controlling that understanding, especially when the student's accomplishment of an utterance depends on the production of gesture in order to either complete the turn or form an intelligible action.

The studied matching gestures, moreover, accomplish other things, for instance, connecting the teacher's turn to that of the student's in a fashion that Sacks (1992a: 716) describes as 'tying', and that Goodwin \& Goodwin (1987) call 'format tying'. It displays the action as a relevant response to a prior action that it is tied to. At the same time, it highlights in retrospect part of the student's verbal production, which the body movements in the student's first gesture compensated for or helped with to be adequately intelligible. In response, the teacher may supply a matching gesture with some adequate extra linguistic items or constructions. The given expressions are heard as learnables and offered as new linguistic glosses, or the enhanced (re)formulations of what the student al ready expressed. The matching gesture as a teaching technique is, thus, used both as a visible display of the problem in the student's production, as well as contributing to a telling that exhibits the reference or meaning of the linguistic expressions that have been sought.

In sum, matching gestures do not just maintain and sustain intersubjectivity in interaction, they are used for pedagogical purposes as well. They are constitutive of the teachable moments when they are used as part of recycling the students' embodied actions to furnish them with new words, new ways of telling and exhibiting (Garfinkel \& Sacks, 1970/1986) in the language learned.

\subsection{Study 4: The intersubjective objectivity of learnables - Theoretical underpinnings of praxeological and dialogical research on opportunities for learning in teacher-student interactivities}

Study 4 deals with some theoretical underpinnings of what is meant by 'learnability' and how 'learnables' are phenomenologically and sociologically defined and investigated within this research project. When looking at the 
organization of interactivities in which some things (here linguistic items and constructs) go through the process of 'becoming' something learnable, understanding that procedure requires a look into the social activity from within (Garfinkel, 1967, 2002: passim), an emic perspective in Pike's (1954) terminology. This allows the researchers to observe and describe, first of all, the endogenous details of action-formation and meaning making processes in which learnables are given sense and salience by participants themselves. It also allows researchers to remain indifferent to what happens as a representation of an 'abstraction' of things in general, and to take 'what happens' into account as what matters to the participants in the there-and-then (see Garfinkel \& Sacks, 1970/1986: 166; see also A rminen, 2008; M acbeth, 2010), and what exists as some particular parts or characteristic traits of an object not intrinsic to it but attributed to (cf. Husserl, 1900-1/2001: 152), highlighted or foregrounded, and accounted for by the participants themselves.

Investigating the organization of mundane practices in teachers' and students' classroom activities, and explicating the rational structures and patterns of their activities will show how members of a community of knowledge/practice are engaged in shaping, organizing and accounting for the current knowledge and practices. It is argued that, like professional sociologists, teachers and students are sensitive to each other's conduct and acts, and hold each other accountable for recognizable practices (Garfinkel, 1967: 3). How they make sense of those practices depends on the socially organized occasions of the uses of those practices.

That is, the practices that are oriented to as learnables are subjective and occasioned, or, in Garfinkel's (1967: 4) terminology, 'indexical'. They, thus, need to be agreed upon by teachers and students as somehow showing an objective reality (in an intersubjective sense, see also Schutz, 1975), also to be used for future purposes.

Therefore, members' accounts of learnables are shaped in the procedure of their uses under the circumstance of their occurrence with regard to the particulars of the context, local participation frameworks (C. Goodwin, 1981), participants' 
methods and modes of expressions. These are constituent features of the learning activities in which learnables are made observable and recognizable as reflected in the members' practices. Teachers and students attend to this 'reflexivity' to 'fit' (Wittgenstein, 1953/2009: 59) their practices to the occasion's practical purposes, and to produce and accomplish something as a learnable, i.e. making it emerge as something rationally adequate as part of the activity in hand. Thus, by talking about an objective reality of learnables, we are talking about an accomplished reality or an accomplished objectivity of them achieved in an intersubjective relation. 


\section{Concluding discussion}

Having investigated the emergence of learnables in classroom interactivities in this research project, I have adopted EM/CA methodology (Garfinkel \& Sacks, 1970/1986), dialogically and praxeologically studied embodied actions, and showed how teachers and students adopt various practices with a diversity of resources to accomplish linguistic learnables. In Swedish as a second language classrooms, within turn-taking practices and in different sequence organizations, I have shown that students as well as teachers orient to a linguistic item or a particular construct as a pedagogical focus emerging in an ongoing activity. This host activity may be an ordinary conversation turning into an instructing/learning project, teaching talk (on vocabulary, grammar, etc.) or a pre-given language learning task.

The analyzed data consists of teacher-student dyadic interactivities in different sequences of actions such as searching for a word, a vocabulary inquiry, explanation, description, correction, formulation and reformulation. The analytic description of these pieces of interactivities shows that what is oriented to as learnables in language learning classrooms may originate in different sources, in verbal and gestural practices and in the material surround (Study 1 ).

Learnables are initially displayed as something searched for, or oriented to as remediable, or improvable items or linguistic constructs either by students (Study 1 and 2) or by teachers (Study 3). In the different studies, I have shown that learnables emerge in sequential activities whether they are unplanned and sequentially initiated by students (Study 1), or initiated and spotted by teachers either in formal tasks, e.g. a grammar task (Study 2), or in informal talk (Study 1 and Study 3).

In the accomplishment of learnables, the significance of the use of tools (e.g. worksheets) and bodily actions (e.g. pointing) is also underlined (Study 2). It is also demonstrated how gestures used by students indicate or compensate for wordfinding problems, and these gestures may be recycled by the teachers for highlighting learnables (Study 3). Teachers' responsive matching gestures are used for achieving and maintaining intersubjectivity, as well as for being a crucial part 
of contributing learnables to the interactivities. It is within these interactivities that the nature of learnables, their operational definiteness, as to what they are and how they should be heard and seen, are pinpointed (see Study 4 for a theoretical discussion).

The studies here have shown how common practices are involved in the accomplishment of learnables in language learning situations. Students may point to something in the immediate environment (Ex.2 in Study 1), pick up a word from the teacher's talk (Ex. 1 in Study 1), or a gesture from the teacher's meta-comment on a linguistic item (Ex. 3 in Study 1), and ask for a linguistic gloss, description, etc. Students and teachers use their bodies (in pointing, in depicting something, etc.) to construct multimodal utterances ( $c f$. C. Goodwin, 1995; Goodwin et al., 2002). In these utterances, bodily actions are used for different practical purposes such as clarification (e.g. Ex.2 in Study 1, Exs. 2 and 3 in Study 3), compensation for an expression (e.g. Ex. 1 in Study 3), display of grammatical relation (Ex. 1 and 2 in Study 2), and completion of an action (Ex. 3 in Study 1 and Ex. 4 in Study 3; cf. Olsher, 2004).

With these embodied practices, students as well as teachers draw one another's attention to something not only in the immediate physical context but in a linguistic context, referring to a lapse in the competence of a student, foregrounding a grammatical concept, a rule or a gloss, problematizing it, topicalizing it, and orienting to it as correctable, improvable and also as learnable.

The orientation to something as a learnable may happen in passing without it being the topic of talk or the business of interchange (e.g. Ex. 2 and 3 in Study 3; cf. Jefferson, 1987; Kurhila, 2006), or it may be topicalized when participants discontinue their ongoing activity to deal with it in a side-sequence (e.g. Ex. 1 in Study $1 ; c f$. J efferson, 1972). Objectifying abstract constructs, operating on them in and through embodied actions, and using material artifacts in local instructing/learning projects have certain theoretical consequences and practical implications. These will be discussed in the following section. 


\subsection{The local accomplishment of instructing/learning projects, their theoretical consequences and practical implications}

Gass and Selinker (1994/2008) describe a mission for second language acquisition (SLA) research. They reformulate the framework of Generative Grammar's theoretical perspective (Chomsky, 1965, 1975) as they themselves also confirm that '[such a] scope of inquiry includes second languages' (Gass \& Selinker, 1994/2008: 3). That is, SLA's mission is to discover the systematic characteristics of second language grammar in the learner's mind:

What is the scope of SLA ? W hat does the study of SLA consist of? It is the study of how second languages are learned. [... It is the study of how learners create a new language system with only limited exposure to a second language. It is the study of what is learned of a second language and what is not learned; [... ] A re there patterns that are common to all learners regardless of the native language and regardless of the language being learned? [... ] In fact the major goal of second language acquisition research is the determination of linguistic constraints on the formation of second language grammars. (Gass and Selinker, 1994/2008: 1-2)

In this dissertation, I have chosen another research paradigm that is, in theory and in the sphere of the subject matter, incommensurable with the abovementioned quote even though its domain of inquiry is similar to that of the cognitivists: How language learning takes place. This paradigm is based on a socially-oriented approach (see e.g. Ortega, 2011), which considers learning a second language as participating in interaction (Y oung \& M iller, 2004; Duff \& Talmy, 2011; Study 1), and getting engaged in the material world and social activities (Lantolf, 2011; Study 2). That is, learning is an embodied achievement (Study 3), co-produced as an achievable phenomenon in interaction (K asper \& W agner, 2011; see also Study 4). So, language learners' 'exposure' to a second language, the construction of its 'grammar', and acquiring its 'rules', and 'constraints' in this process are not just 
mental abstract phenomena, but concrete social ones, recognizable and examinable in empirical data.

\subsubsection{Theoretical consequences}

Considering learning as a social process (Lave \& Wenger, 1991; cf. Brouwer \& Wagner, 2004; Duff \& Talmy, 2011), this research project has focused on actions and procedures (cf. Ortega, 2011: 168; see Study 4) in and through which opportunities for learning are made possible. Participants mobilize different resources (Study 1), attend to public visible actions (Study 2), use material artifacts (Study 1 and 2), and orient to learnables and achieve them in and through embodied actions (Study 1-3).

W hereas the traditional cognitive approach (e.g. Gass \& Selinker, 1994/2008) regards language acquisition as 'having', 'possessing' linguistic knowledge (equal to linguistic competence), which is posited as an abstract system in an individual's mind/brain, this research project shows that cognition may be found in the intersubjective world (see also M ondada \& Pekarek Doehler, 2004; K asper, 2009). Orienting to learnables, and gaining knowledge about them - construction and development of knowledge - are the procedural outcome of 'doing of things together', 'socializing', and 'participating' in interactivities (see a more elaborate discussion in Sfard, 1998; L arsen-Freeman, 2004; R. Ellis, 2010; A tkinson, 2011; see also Y oung \& M iller, 2004; Hall et al., 2011). So, what is learned is a social achievement, emerging within social practices (Schieffelin \& Ochs, 1986), rather than being a stock of knowledge in someone's mind being passed on to learners in an abstract way.

Consequently, knowledge, cognition, and competence are not confined to the individual mind, but are socially situated, embodied, distributed and achievable in interactivities (Goodwin, 1994, 2000b, 2013; M ondada \& Pekarek Doehler, 2004; Heritage, 2005; A ntaki, 2006; M aynard, 2006; Potter, 2006; Streeck et al., 2011; Linell, 2014). For competence is not abstract knowledge but the ability to perform (Wittgenstein, 1953/2009), and to accomplish social activities. Its development entails some social actions and procedures. 


\subsubsection{Practical implications}

The procedures involving social learning and pedagogy have particular characteristics specific to their events, activities and practices (cf. Csibra \& Gergely, 2006: 257-258). They do not deal only with the pre-formed formal objects which are usually given priority in teaching because of quantitative measurements like frequency of use ( $c f$. Tomasello, 2003: 15; Eskildsen, 2012) as one of the key elements of learning and measuring that learning (see M ilton, 2009). They also involve learnables that are emergent, situated, co-produced, and reified on the circumstance of their occurrences (Studies 1-4; see also M arkee, 2000, 2004; Seedhouse, 2004). What students learn cannot always be predicted beforehand or delimited in advance.

Teaching and learning a language are practical hands-on interactivities. As shown in this research project, what is at issue in these interactivities in second language learning classrooms are the details of 'communicative events' (Hymes, 1964: 13), the practices in 'local communicative projects' (Linell, 2009: 178), and the activities in teachers' and students' courses of action involving language, i.e. languaging (Becker, 1991). In a language learning classroom, language is oriented to as an essential part of communicative events. However, this research project shows that in the construction of communicative events in classrooms, language is not the only component. $\mathrm{N}$ either is it taken as a device in the abstract, but as a functional device with a functional relativity in the circumstance of its use, in relation to the social activity, to both interpersonal and physical contexts. What teachers do in a language learning class is to offer language as a means of communication and an object of inquiry at the same time. Teachers and students treat the language as a social object that can be used as resource for communication, and also as the object of an inquiry that can be talked about, shown, worked on, parsed, acted upon, and organized in a special way.

Teachers and students of a language treat the language learned as a domain of a profession. Students learn how to see a linguistic item as a special category with some characteristics attributed to it. They learn how to hear words and phrases, how to construct them, and how to deconstruct them (Study 2). They achieve what 
is called a professional vision (C. Goodwin, 1994) or what I have called an instructed vision (Study 2) in and through which they see (on the paper, on the board, etc.) and understand language differently. They are trained to use language as a resource with which to accomplish different social actions, and they can also analyze it. They learn alternative ways of telling and exhibiting their mastery of language (see Garfinkel \& Sacks, 1970/1986) in a variety of circumstances. That is, they develop competence in languaging, in how to use language for doing social activities.

The analyses show that in classroom interactivities, teachers and students, in order to co-build competence, make use of one another's bodies (Ex. 3, Study 1; see also Study 4), and material surround to work on linguistic items. They use artifacts such as papers (Study 2), the whiteboard, transparency sheets (using e.g. overheads, see Ex. $3 \mathrm{~b}$ in section 2.4. here). They use mundane and concrete practices and in this way, they treat even abstract grammatical glosses, concepts and relations as concrete objects, something that can be pointed at, talked about and oriented to on a visible surface that all have access to. The objectification of abstract constructs, operating on them in and through embodied actions, and using material artifacts in teaching and learning language show the primacy of social activities in the process of learning. This has certain implications not only for teaching and learning planning and styles, but also for future research.

\subsection{Implications for future research}

Research on second language learning from an EM/CA perspective is growing (see Firth \& Wagner, 2007; Kasper \& Wagner, 2011; Hall \& Pekarek Doehler, 2011; Gardner, 2013, etc.). There are now different cohorts of researchers that are concerned with second language learning, from researchers adherent or sympathetic to the Chomskyan universalist view of grammar (e.g. Gass \& Selinker, 1994/2008), to other groups of researchers, emergentists (e.g. M acW hinney, 1998, 2005), evolutionists and usage-based analysts (N. Ellis, 2008; Eskildsen, 2012; cf. Tomasello, 2008), socioculturalists (e.g. Lantolf, 2011), and sociocognitivists (e.g. Atkinson, 2002; Churchill et al., 2010). EM/CA with its 
dialogical and praxeological underpinnings proves to be an illuminating research domain in the field of education (social learning and pedagogy). It provides the methodological and analytic tools to see the details of accomplishing learning activities, examining what practices are used by teachers and students, experts and novices, trainers and trainees, etc. in the procedure of achieving instructing activities.

In their critical review, Coffield, Moseley, Hall and Ecclestone (2004) identified 71 models of language learning styles, most of which concerned with individual progress while taking the role of others, contexts and environments either for granted or as peripheral. It seems to be the case that whereas these models are being extensively produced, there are scant empirical studies providing reliable data-driven results to prove their pedagogical impact in practice (see Coffield et al., 2004). Therefore, there seems to be an urge for attention to the dialogical nature (Linell, 2009) of interactivities with all its detailed complexity in classrooms.

The theoretical frames within second language research usually acknowledge learner agency (Larsen-Freeman, 1997), but it is only seldom the case that these models take the actual methods used by learners in learning activities into consideration. For many learning models, the assumed identity of novice language users in classrooms is a taken for granted quality of the participants, or 'a linguistic fact-of-life' (Carroll, 2000: 72). Students are automatically called 'learners' and teachers 'teachers' throughout sequences of classroom interaction simply on account of these prefigured labels. What is missed, of course, is the fact that relevant identities may well change over the course of unfolding interactional sequences (see e.g. Drew \& Sorjonen, 1997).

What Firth and Wagner (1997) called for, similar to what Hymes (1964) proposed in his cross-disciplinary 'ethnographies of communication', is a call for a 'fresh kind of data' to investigate 'the use of language in contexts of situations so as to discern patterns proper to speech activity' (Hymes, 1964: 3; cf. Firth \& $W$ agner, 1997: 286). Language in this view is not regarded as a given code or a frame of reference, separated from personal traits or interpersonal relations, 
sociological and anthropological factors, history, the ecology of communication, and the like.

In this fresh broader look at language and its use, designing abstract mental models of grammar is not the primary research objective. What is at issue is the 'communicative event' (Hymes, 1964: 13), and the activity we do with language, i.e. languaging (B ecker, 1991). In these social events, the account for the event is emically made from the view of the participants in that situation, event and culture (Pike, 1954). So, what might also be interesting (and crucial for understanding the nature of learning) is laid out in EM/CA to appraise teachers' and students' own display of their behavior or what Hymes (1964: 14) called 'their home-made models' ( $c f$. 'folk theory' that some other anthropologists defined as the core of any anthropological theory, e.g. Bohannan, 1959; $c f$. 'folk method' in ethnomethodology, in Garfinkel, 1967).

The description and explanation of what language consists in are now bound up with the provision of evidence from the functional operations of language in real social situations. This has become the grounds across many disciplines for having the theories be subject to empirical tests for examining their adequacy of logical and empirical viability. So, the examination of the rationale of communication may result in proposing new learning and teaching theories.

When skepticism undermines any speculations or generalizations relying only on experimental tests and abstracted mental models without paying enough attention to the real learning activities in real events, the real data from real situations exhibiting the howness of learning practices would be an illuminating source for further development of research in second language learning.

Swedish as a second language is no exception. Paying attention to the social procedures in learning activities interdependent with the actions made cooperatively with others, and contexted in particular circumstances, are pivotal to our understanding of the social reality of language learning. This dissertation remains agnostic to the extent and depth of the relation between the opportunities produced for teaching and learning (emergence of learnables) and language development. It requires further research to examine learners' language 
development either in local communicative projects and small interactivities, or in more longitudinal data analyzing learners' performance across time (see e.g. B rouwer \& Wagner, 2004; M arkee, 2011).

Research on second language learning, consequently, needs to pay systematic attention to the role of others and environment (context, relations, history, interaction, biographies, and the like) when theorizing this relation and designing learning models, styles, tests, teaching and learning strategies, etc. What students can do together, also with the use of artifacts and technology (e.g. A mir, 2013; Kunitz, 2013; M usk, 2013) should also be considered in the examination of language learning and development (see arguments for interactional competence in Hall et al., 2011).

A longside these new concerns, a disparate pressure also comes from the actual enterprise of learning and pedagogy in societies to supply some methodic responses to the demands of the field: how students learn languages and how their needs should be met (see e.g. R. Ellis, 2012). As a result of these increasing demands for reality check, there are now a growing number of language learning researchers who have stopped philosophizing acquisition before analyzing empirical data and learners' linguistic/communicative/interactional development at all levels of microgenetic, ontogenetic and sociogenetic changes (Lehre \& Schauble, 2011). N ew attempts in research are directed toward the practicality of any theoretical and methodological proposals (see K oschmann, 2011). These have resulted, all in all, in the social turn in the second language learning research area (see Block, 2003), which shapes a significant part of the future in this research domain.

Detailed studies of classroom interactivities may raise our 'awareness' about the ways and methods that we actually have at our disposal for improving pedagogy. What this dissertation suggests, which should not be neglected after all, is that teaching and learning languages are not only done by talking, but by acting upon materials, by showing, seeing, co-operating and interacting with people through embodied practices, and thus creating sustainable ways of organizing what we can call knowledge. 


\section{References}

Alibali, M. W., Flevares L. M. \& Goldin-Meadow, S. (1997). A ssessing knowledge conveyed in gesture: Do teachers have the upper hand? Journal of Educational Psychology, 89(1), 183-193.

A mir, A \& M Msk, N. (2013). Language policing: micro-level language policy-in-process in the foreign language classroom. Classroom Discourse, 4(2), 151-167.

A nderson P. \& Osman, A . (2008). Recognition of prior learning as a practice for differential inclusion and exclusion of immigrants in Sweden. Adult Education Quarterly, 59(1), 4260.

A ndrén, M. (2010). Children's gestures from 18-30 months. PhD. Diss. Lund: Lund U niversity Press.

A ntaki, C. (2006). Producing a 'cognition'. Discourse Studies, 8(1), 9-15.

A nward, J. (1983). Språkbruk och språkutveckling i skolan [Language use and language development in the school]. Lund: Liber Förlag.

A rminen, I. (2008). Scientific and 'radical' ethnomethodology: From incompatible paradigms to ethnomethodological sociology. Philosophy of the Social Sciences, 38, 167-191.

A rnold, L. (2012). Dialogical embodied action: Using gesture to organize sequence and participation in instructional interaction. Research on Language and Social Interaction, 45(3), 269-296.

A tkinson, D. (2002). Toward a sociocognitive approach to second language acquisition. The Modern Language Journal, 86(4), 525-545.

A tkinson, D. (2011). Alternative approaches to second language acquisition. London: Routledge.

A tkinson, J. M . \& Heritage, J. (1984). Structure in social action - Studies in conversation analysis. Cambridge: Cambridge University Press.

Bachman, L. F. (1990). Fundamental consideration in language testing. Oxford: Oxford University Press.

Bannert, R. (1984). Problems in learning Swedish pronunciation and in understanding foreign accent. Folia Linguistica 18(1-2), 193-222.

B ateson, G. (1972). Steps to an ecology of mind. Chicago: U niversity of Chicago Press.

Bateson, G. \& M ead M. (1942). Balinese character, a photographic analysis. N ew Y ork: The New Y ork A cademy of Sciences. 
B ecker, A ., L. (1991). L anguage and languaging. Language and Communication, 11(2), 3335.

Beijer M. \& Bolin, S. (2003). Curriculum development for social inclusion in Sweden. Prospects, 33(1), 51-62.

Bellack, A ., K liebard, H. K. Hyman, R. T. \& Smith, F. L. J r. (1966). The language of the classroom. $\mathrm{N}$ ew $\mathrm{Y}$ ork: Teachers College Press.

Block, D. (1996). Not so fast: Some thoughts on theory culling, relativism, accepted findings and the heart and soul of SLA . Applied Linguistics, 17, 63-83.

Block, D. (2003). The social turn in second language acquisition. Edinburgh: Edinburgh U niversity Press.

B ohannan, P. (1959). A nthropological theories. Letters. Science, 129(3345), 129-130.

B oye-M øller, M . (1973). L anguage training for immigrant workers in Sweden. International Labour Review, 108(6), 505-515.

Bremme, D. W. \& Erickson, F. (1977). Relationships among verbal and nonverbal classroom behaviors. Theory into Practice, 16(3), 153-161.

B roth, M . (2008). The studio interaction as a contextual resource of TV-production. Journal of Pragmatics, 40, 904-926.

B roth, M \& \& Forsberg Lundell, F. (2013). Napouléon's sequential heritage. U sing a student error as a resource for learning and teaching pronunciation in the French foreign language classroom. Classroom Discourse, 4(1), 89-109.

B roth, M . \& M ondada, L. (2013). Walking away: The embodied achievement of activity closings in mobile interaction. Journal of Pragmatics, 47, 41-58.

B rouwer, C. E. (2003). Word searches in N NS-N S Interaction: opportunities for language learning? The Modern Language Journal, 87, 534-545.

Brouwer, C. E., Rasmussen, G. \& Wagner, J. (2004). Embedded corrections in second language talk. In R. Gardner \& J. Wagner (Eds.), Second language conversations, (pp. 75-92). London: Continuum.

Brouwer, C. E. \& Wagner, J. (2004). Developmental issues in second language conversation. Journal of Applied Linguistics, 1.1, 29-47.

B rown, A \& \& Gullberg, M. (2010). Changes in encoding path of motion in a first language during acquisition of a second language. Cognitive Linguistics, 21(2), 263-286.

Brown, A. \& Gullberg, M. (2011). Bidirectional cross-linguistic influence in even conceptualization? Expressions of path among Japanese learners of English. Bilingualism, Language and Cognition, 14(1), 79-94. 
Carlson, M. (2002). Svenska för invandrare - Brygga eller gräns? Syn på kunskap och lärande inom sfi-undervisningen [Swedish Language Courses for Immigrants - Bridge or border? On views of knowledge and learning in SFI education]. Gothenburg Studies in Sociology, Department of Sociology: Gothenburg U niversity.

Carlson, M. (2006). Images and values in textbooks and practice: Language courses for immigrants in Sweden. In M. Carlson, A. Rabo \& F. Gök (Eds.), Education in multicultural societies - Turkish and Swedish perspectives. Transactions Series. (Vol. 18, pp. 123-140). B romma, Sweden: Swedish Research Institute in Istanbul.

Carroll, D. (2000). Precision timing in novice-to-novice L 2 conversations. Issues in Applied Linguistics, 11, 67-110.

Cazden, C. B. (1986). Classroom discourse. In M. C. Wittrock (Ed.), Handbook of research on teaching, (pp. 432-463). New York: Macmillan.

Cazden, C. B. (2001). Classroom discourse: The language of teaching and learning. Portsmouth, $\mathrm{NH}$ : Heinemann.

Cazden, C. B. \& Hymes D. (1978). Narrative thinking and storytelling rights: a folklorist's clue to a critique of education. Keystone Folklore, 22(1-2), 21-35.

Cekaite, A. (2006). Getting started. Children's participation and language learning in an L2 classroom. PhD. Diss., Linköping: Linköping U niversity Press.

Cekaite, A. \& Björk-Willén, P. (2012). Peer group interaction in multilingual educational settings: Co-constructing social order and norms for language use. International Journal of Bilingualism, 17(2)-174-188.

Chomsky, N. (1959). Reviews: V erbal behavior by B. F. Skinner. Language, 35(1), 26-58.

Chomsky, N. (1965). Aspects of the theory of syntax. Cambridge, M ass.: The M IT Press.

Chomsky, N. (1975). Reflections on language. N ew Y ork: Pantheon B ooks.

Chomsky, N. (1993). On the nature, use, and acquisition of language. In. A. I. Goldman (Ed.), Readings in philosophy and cognitive science. Cambridge, M ass.: The M IT Press. (Original work published 1987).

Church, R. B. \& Goldin-M eadow, S. (1986). The mismatch between gesture and speech as an index of transitional knowledge. Cognition, 23, 43-71.

Churchill, E., Okada, H., Nishino, T. \& Atkinson, D. (2010). Symbiotic gesture and sociocognitive visibility of grammar in second language acquisition. The Modern Language Journal, 94, 234- 253.

Clark, A. (1989). Microcognition: Philosophy, cognitive science, and parallel distributed processing. Cambridge, M ass.: The M IT Press.

Clark, A \& \& Chalmers, D. (1998). Extended mind. Analysis, 58(1), 7-19. 
Clark, H. H. (1996). Using language. Cambridge: Cambridge University Press.

Clark, J. (1969). Competence and performance: A missing link. Audiovisual Language Journal, 7(1), 31-36.

Coffield, F., M oseley, D., Hall, E \& Ecclestone, K . (2004). Learning styles and pedagogy in post-16 learning. A systematic and critical review. London: Learning and Skills Research Centre.

Condon, W. S. \& Ogston, W. D. (1966). Sound film analysis of normal and pathological behavior patterns. The Journal of Nervous and Mental Disease, 143(4), 338-347.

Condon, W. S. \& Ogston, W. D. (1967). A segmentation of behavior. Journal of Psychiatric Research, 5, 221-235.

Cromdal, J. (2013). Bilingual and second language interactions: Views from Scandinavia. International Journal of Bilingualism, 17(2), 121-131.

Csibra, G. \& Gergely G. (2006). Social learning and social cognition: the case for pedagogy. In Y. M unakata \& M.H. Johnson (Eds.), Processes of change in brain and cognitive development. Attention and Performance, XXI (pp. 249-274). Oxford: Oxford University Press.

Delbos, L. (1899). Notes on the learning and teaching of modern languages. The Modern Quarterly of Language and Literature. 2(5), 58-66.

Deppermann, A . (2013). Turn-design at turn-beginnings: Multimodal resources to deal with tasks of turn-construction in German. Journal of Pragmatics, 46, 91-121.

Dewey, J. (1915). The school and society. Chicago, III.: The U niversity of Chicago Press.

Drew, P. \& Heritage, J. (1992). Talk at work - Interaction in institutional settings. Cambridge: Cambridge U niversity Press.

Drew, P. \& Sorjonen M-L (1997). Institutional dialogue. In T. van Dijk (Ed.), Discourse studies: a multidisciplinary introduction, Volume 2, Discourse as social interaction, (pp. 92-118). L ondon: SA GE

Duff, P. A. \& Talmy, S. (2011). Language socialization approaches to second language acquisition: Social, cultural, and linguistic development in additional languages. In D. A tkinson (Ed.), Alternative approaches to second language acquisition, (pp. 95-116). London: Routledge.

Duranti, A . (1997). Linguistic anthropology. Cambridge: Cambridge U niversity Press.

Duranti, A. \& Goodwin, C. (1992). Rethinking context. Language as an interactive phenomenon. Cambridge: Cambridge University Press.

Efron, D. (1941). Gesture, Race and Culture. The Hague: M outon. 
Egbert, M. M. (1998). M iscommunication in language proficiency interview of first-year German students: A comparison with natural conversation. In R. Y oung \& A. W. He (Eds.), Talking and testing: Discourse approaches to the assessment of oral proficiency, (pp. 149-172). A msterdam: J ohn B enjamins.

Ekman, P. \& Friesen, W.V. (1969). The repertoire or nonverbal behavior: categories, origins, usage, and coding. Semiotica, 1, 49-98.

Ekström, A . (2012). Instructional work in textile craft. Studies of interaction, embodiment and the making of objects. PhD. Diss., Stockholm: Stockholm University Press.

Ekström, A ., Lindwall, 0 \& Säljö, R. (2009). Questions, instructions and modes of listening in the joint production of guided action: $A$ study of student-teacher collaboration in handicraft education. Scandinavian Journal of Educational Research, 53(5), 497-514.

Ellis, N. (2008). The dynamics of second language emergence: Cycles of language use, language change, and language acquisition. The Modern Language Journal, 92, 232249.

Ellis, R. (1990). Instructed second language acquisition: Learning in the classroom. Oxford: B. Blackwell.

Ellis, R. (2010). Second language acquisition, teacher education and language pedagogy. Language Teaching , 43:2, 182-201.

Ellis, R. (2012). Language teaching research and language pedagogy. Malden, MA and Oxford: W iley-Blackwell.

Elmeroth, E. (2003). From refugee camp to solitary confinement: Illiterate adults learn Swedish as a second language. Scandinavian Journal of Educational Research, 47(4), 431-449.

Enfield, N. J., K ita S. \& de Ruiter, J. P (2007). Primary and secondary pragmatic functions of pointing gestures. Journal of Pragmatics, 39, 1722-1741.

Eskildsen, S. W. (2012). L 2 negation construction at work. Language Learning, 62(2), 335372.

Estes, W. K., Newell. A., A nderson. J. R., Brown, J. S., Feigenbaum, E. A., Greeno. J., Hayes, P. J., Hunt, E., K osslyn, S. M., M arcus, M \& \& Ullman, S. (1983). Report of the Research Briefing Panel on Cognitive Science and Artificial Intelligence. Research Briefings 1983. Washington. DC: N ational A cademy Press.

Erickson, F. (1973). What makes school ethnography 'ethnographic?' Council on Anthropology and Education, 4(2), 10-19.

Erickson, F. (1982). Classroom Discourse as Improvisation: Relationships Between A cademic Task Structure and Social Participation Structure in Lessons. In L. C. 
W ilkinson (Ed.), Communication in the Classroom, (pp-153-182). N ew Y ork: A cademic Press.

Erickson, F. \& Schult, J. (1978). When is a context? Some issues and methods in the analysis of social competence. Quarterly Newsletter of the Institute for Comparative Human Development, 1(2), 5-10.

Firth, A . (2009). Doing not being a foreign language learner: English as a lingua franca in the workplace and (some) implications for SLA. IRAL, 47: 127-156.

Firth, A. \& Wagner, J. (1997). On discourse, communication and (some) fundamental concepts in second language acquisition research, The Modern Language Journal, 81 (3), 285-300.

Firth, A. \& Wagner, J. (2007). Second/foreign language learning as a social 54 accomplishment: Elaborations on a reconceptualized SLA. The Modern Language Journal, 91, 800- 818.

Gardner, R. (2013). Conversation analysis in the classroom. In. J. Sidnell and T. Stivers (Eds.). The handbook of conversation analysis, (pp. 593-611). Malden, M A : B lackwell Publishing.

Gardner, R. \& Wagner, J. (2004). Second language conversations. London: Continuum.

Garfinkel, H. (1967). Studies in Ethnomethodology. N ew J ersey: Prentice Hall Inc.

Garfinkel, H. (1996). Ethnomethodology's program. Social Psychology Quarterly, 59(1), 521.

Garfinkel, H. (2002). Ethnomethodology's program. Working out Durkheim's aphorism, A. W. Rawls (Ed.). Lanham, M aryland: Rowman \& Littlefield Publishers.

Garfinkel, H., Lynch, M. \& Livingston, E. (1981). The work of a discovering science construed with materials from the optically discovered pulsar. Philosophical Social Science, 11, 131-158.

Garfinkel. H. \& Sacks. H. (1986). On formal structures of practical actions. In H. Garfinkel (Ed.), Ethnomethodological Studies of Work (pp. 160-193). London and New Y ork: Routledge \& Kegan Paul. (Original work published 1970).

Gass, S. M . (1996). Second language acquisition and linguistic theory: The role of language transfer. In W. C. Ritchie \& T. K. Bhatia (Eds.), Handbook of second language acquisition, (pp. 317-345). San Diego: A cademic Press.

Gass, S. M . \& Selinker, L. (2008). Second language acquisition - an introductory course. N ew Y ork: Routledge. (O riginal work published 1994).

Gentner, D. \& Goldin-M eadow, S. (2003). Language in mind. Advances in the study of language and thought. Cambridge, M A: The M IT Press. 
Gibson, J. J. (1979). The ecological approach to visual perception. Hillsdale, N J: Erlbaum.

Goffman, E. (1956). Presentation of self in everyday life. Edinburgh: University of Edinburgh.

Goffman, E. (1963). Behavior in public places. N ew Y ork, NY : F ree Press.

Goffman, E. (1967). Interaction ritual: Essays in face-to-face behavior. Philadelphia: University of Pennsylvania Press.

Goffman, E. (1974). Frame analysis. N ew Y ork: Harper \& Row.

Goffman, E. (1981). Forms of talk. Philadel phia: University of Pennsylvania Press.

Goldin-M eadow, S. (2003). Hearing gesture. How our hands help us think. Cambridge, $M$ ass.: Belknap Press of $\mathrm{H}$ arvard U niversity Press.

Goodwin, C. (1979). The interactive construction of a sentence in natural conversation. In G. Psathas (Ed.), Everyday language: Studies in Ethnomethodology (pp. 97-121). NY: Irvington Publishers.

Goodwin, C. (1981). Conversational organization - Interaction between speakers and hearers. N ew Y ork: A cademic Press.

Goodwin, C. (1994). Professional vision. American Anthropologist, 96(3), 606-633.

Goodwin, C. (1995). Co-constructing meaning in conversation with an aphasiac man. Research on Language and Social Interaction, 28(3), 233-260.

Goodwin, C. (2000a). A ction and embodiment within situated human interaction. Journal of Pragmatics, 32, 1489-522.

Goodwin, C. (2000b). Practices of color classification. Mind, Culture, and Activity, 7(1/2), 19-36.

Goodwin, C. (2000c). Practices of seeing. Visual analysis: an Ethnomethodological approach. In T. van Leeuwen \& C. J ewitt (Eds.), Handbook of visual analysis, (pp. 157182). London: Sage Publications.

Goodwin, C. (2002). Time in action. Current Anthropology, 43, Supplement, S19-S35.

Goodwin, C. (2003). The body in action. In J. Coupland \& R. Gwyn (Eds.), Discourse, the body and identity, (pp. 19-42). N ew Y ork: Palgrave/M acmillan.

Goodwin, C. (2007a). Environmentally coupled gesture. In. S. D. Duncan, J. Cassell, \& E. T. Levy (Eds.), Gesture and the dynamic dimension of language, (pp. 195-212). A msterdam: John Benjamins.

Goodwin, C. (2007b). Interactive footing. In E. Holt \& R. Clift (Eds.), Reporting talk, (pp. 16-46). Cambridge: Cambridge U niversity Press.

Goodwin, C. (2013). The co-operative, transformative organization of human action and knowledge. Journal of Pragmatics, 46, 8-23. 
Goodwin, C. \& Duranti, A . (1992). Rethinking context: A n introduction. In A . Duranti \& C. Goodwin (Eds.), Rethinking context, (pp. 1-42). Cambridge: Cambridge University Press.

Goodwin, M. H. (1980). Processes of mutual monitoring implicated in the production of description sequences. Sociological Inquiry, 50, 303-317.

Goodwin, M. H. (1990). He-said-she-said. Talk as social organization among black children. Bloomington: Indiana U niversity Press.

Goodwin, M. H. (1997). Byplay: Negotiation evaluation in storytelling. In G. R. Guy, C. Feagin, D. Schiffrin \& J. Baugh (Eds.). Towards a social science of language. Papers in honor of William Labov, Vol. 2. Social interaction and discourse structures. A msterdam. John B enjamins.

Goodwin, C. \& Goodwin, M. H. (1986). Gesture and coparticipation in the activity of searching for a word. Semiotica, 62(1/2), 51-75.

Goodwin, C. \& Goodwin, M. H. (1987). Concurrent operations on talk: notes on the interactive organization of assessment. IPrA Papers in Pragmatics, 1(1), 1-52.

Goodwin, C. \& Goodwin, M. H. (1992). Assessment and construction of context. In A. Duranti \& C. Goodwin (Eds.), Rethinking context, (pp. 147-190). Cambridge: Cambridge University Press.

Goodwin, C., Goodwin, M. H.\& Olsher, D. (2002). Producing sense with nonsense syllables: Turn and sequence in conversation with a man with sever aphasia. In C. E. Ford, B. A. Fox \& S. A. Thompson (Eds.), The language of turn and sequence, (pp. 5681). Oxford: Oxford University Press.

Granberg, N. (2001). The dynamics of second language learning. A longitudinal and qualitative study of an adult's learning of Swedish. PhD. Diss., U meå: U meå U niversity, Larsson \& Co:s Tryckeri AB.

Gullberg, M. (1998). Gesture as a communication strategy in second language discourse. A study of learners of French and Swedish. PhD. Diss., L und: L und U niversity Press.

Gullberg, M. (2008), Gestures and second language acquisition. In P. Robinson \& N. C. Ellis (Eds.), Handbook of cognitive linguistics and second language acquisition, ( $\mathrm{pp}$. 276-305). New Y ork: Routledge.

Gumperz, J. J. (1982). Discourse strategies. Cambridge: Cambridge U niversity Press.

Gumperz, J. J. (1992). Contextualization revisited. In P. A uer \& A. di Luzio (Eds.), The contextualization of language, (pp. 39-54). A msterdam: J ohn B enjamins.

Gumperz, J. J. \& Hymes, D. (1972). Directions in sociolinguistics: The ethnography of communication. N ew Y ork: Holt, Rinehart and Winston. 
Gustavsson, L. (1988). Language taught and language used-Dialogue processes in dyadic lessons of Swedish as a second language compared with non-didactic conversations. PhD. Diss., Linköping: Linköping U niversity Press.

Hall, J. K., Hellermann, J.\& Pekarek Doehler, S. (2011). L2 interactional competence and development. Kindle Edition. B ristol: M ultilingual M atters.

Harris, Z. S. (1952). Discourse analysis. Language, 28(1), 1-30.

Hatch, E. M. (1978). Discourse analysis and second language acquisition. In E. M. Hatch (Ed.), Second language acquisition: A book of readings (pp. 401-435). Rowley, M A: N ewbury House.

He, A. W. (2004). CA for SLA: A rguments from Chinese language classroom. The Modern Language Journal, 88(4), 568-582.

Heath, C. (1984). Talk and recipiency: Sequential organization in speech and body movement. In M. A tkinson \& J. Heritage (Eds.). Structures of social action - Studies in conversation analysis, (pp. 247-265). Cambridge: Cambridge U niversity Press.

Heath, C. \& Luff, P. (2007). Ordering competition: The interactional accomplishment of the sale of art and antiques at auction. The British Journal of Sociology, 58(1), 63-85.

Heath, C., Luff, P. \& Svensson, M. S. (2007). Video and qualitative research: A nalysing medical practice and interaction. Medical Education, 41, 109-116.

Heidegger, M. (1967). What is a thing?, W. B. Barton, Jr. \& V. Deutsch (Trans.). South Bend, Indiana: Gateway Editions.

Hellermann, J. (2007). The development of practices for action in classroom dyadic interaction: Focus on talk openings. The Modern Language Journal, 91, 83-96.

Hellermann, J . (2009). Practices for dispreferred responses no by a learner of English. IRAL, $47,95-126$.

Heritage, (1984). Garfinkel and ethnomethodology. Cambridge: Polity Press.

Heritage, J. (2005). Cognition in discourse. In H. Te Molder \& J. Potter (Eds.). Conversation and cognition, (pp. 184-202). Cambridge: Cambridge U niversity Press.

Heritage, J. (2012). Epistemics in Action: Action formation and territories of knowledge. Research on Language and Social Interaction, 45(1), 1-29.

Hindmarsh, J., Raymond, P. \& Dunne, S. (2011). Exhibiting understanding: The body in apprenticeship. Journal of Pragmatics, 43, 489-503.

H olmqvist, M ., Tullgren, C. \& B rante, G. (2011). The object of learning - before, during and after a learning situation. Journal of Systematics, Cybernetics and Informatics, 9(2), 6773.

Holquist, M . (1990). Dialogism: Bakhtin and his world. London and N ew Y ork: Routledge. 
Husserl, E. (2001). The shorter logical investigations, J. N. Findlay (Trans.). London and N ew Y ork: Routledge. (Original work published in two volumes 1900-1901).

Hutchins, E. (1995). Cognition in the wild. Cambridge, M ass.: M IT Press.

Hymes, D. H. (1964). Introduction: Toward ethnographies of communication. America Anthropologists, 66(6), Part 2: The ethnography of communication, 1-34.

Hymes, D. H. (1977). Qualitative/quantitative research methodologies in education: A linguistic perspective. Anthropology and Education Quarterly, 8(3), 165-176.

Hymes, D. H. (1980). Educational ethnology. Anthropology and Education Quarterly, 11(1), 3-8.

Håkansson. G. (1987). Teacher Talk. How Teachers Modify their Speech when Addressing Learners of Swedish as a Second Language. PhD. Diss., L und: L und U niversity Press.

J efferson, G. (1972). Side sequences, In Sundow, D., Studies in social interaction, (pp.294451). N ew Y ork: The Free Press.

Jefferson, G. (1973). A case of precision of timing in ordinary conversation: Overlapped tag-positioned address terms in closing sequences. Semiotica, 9(1), 47-96.

J efferson, G. (1987). On exposed and embedded correction in conversation. In G. Button \& J. R. E. Lee (Eds.). Talk and social organization, (pp. 86-100). Clevedon: M ultilingual M atters.

Jewitt, C. (2011). The Routledge handbook of multimodal analysis. London \& N ew Y ork: Routledge.

Jansson, G. \& Plejert, C. (2014). Taking a shower. M anaging a potentially imposing activity in dementia care. To appear in Journal of Interactional Research in Communication Disorders.

K asper, G. (2004). Participant orientation in German conversation-for-learning. The Modern Language Journal, 88(4), Special Issue: Classroom talks, 551-567.

K asper, G. (2009). Locating cognition in second language interaction and learning: Inside the skull or in public view? IRAL, 47, 11-36.

Kasper, G.\& Wagner, J. (2011). A conversation-analytic approach to second language acquisition. In D. Atkinson (Ed.), Alternative approaches to second language acquisition, (pp. 117-142). London and N ew Y ork: Routledge.

K eevallik, L. (2010). B odily quoting in dance correction. Research on Language and Social Interaction, 43(4), 401-426.

K endon, A . (1970). M ovement coordination in social interaction: Some examples described. Acta Psychologica, 32, 100-125. 
Kendon, A. (1977). Studies in the behavior of social interaction. Bloomington: Indiana U niversity Press.

K endon, A . (1990). Conducting interaction - Patterns of behavior in focused encounters. Cambridge: Cambridge U niversity Press.

K endon, A . (1997). Gesture. Annual Review of Anthropology, 26, 109-128.

K endon, A . (2004). Gesture: Visible action as utterance. Cambridge: Cambridge University Press.

K oschmann, T. (2011). Theories of learning and studies of instructional practices. $\mathrm{New}$ Y ork, NY : Springer.

K oschmann, T. \& LeBaron, C. (2002). Learner articulation as interactional achievement: studying the conversation of gesture. Cognition and Instruction, 20(2), 249-282.

K oschmann, T., LeBaron, C., Goodwin, C. \& Feltovich, P. (2011). 'Can you see the cystic artery yet?' A simple matter of trust. Journal of Pragmatics, 43, 521-541.

K oschmann, T., Zemel, A., Conlee-Stevens, M., Y oung, N. P., Robbs, J. E. \& Barnhart, A. (2005). How do people learn: Members' methods and communicative mediation. In R. Bromme, F.W. Lesse \& H. Spada (Eds.), Barriers and biases in computer mediated knowledge communication and how they may be overcome, (pp. 265-294). N ew Y ork, NY : Springer.

Koshik, I. (2002). Designedly incomplete utterances: a pedagogical practice for eliciting knowledge displays in error correction sequences. Research on Language and Social Interaction, 35(3), 277-309.

K ramsch, C. J. (1983). Interaction in the classroom: Learning to negotiate roles and meanings. Die unterrichtspraxis / Teaching German, 16(2), 175-190.

K rashen, S. (1981). Second language acquisition and second language learning. Oxford: Pergamon Press.

K ress, G. \& van Leeuwen, T. (2001). Multimodal discourse. N ew Y ork: Oxford University Press.

K unitz, S. (2013). Group planning among L2 learners of Italian: A conversation analytic perspective. PhD. Diss. U rbana, Illinois: U niversity of Illinois at U rbana-Champaign.

Kurhila, S. (2001). Correction in talk between native and nonnative speaker. Journal of Pragmatics. 33, 1083-1110.

K urhila, S. (2004). Clients or language learners - Being a second language speaker in institutional interaction. In R. Gardner \& J. Wagner (Eds.), Second language conversations, (pp. 58-74). London: Continuum.

K urhila, S. (2006). Second language interaction. A msterdam: John B enjamins. 
Labov, W. (1966). The social stratification of English in New York City. W ashington, DC: Center for A pplied Linguistics.

Lantolf, J. P. (2000). Sociocultural theory and second language learning. Oxford: Oxford University Press.

Lantolf, J. P. (2011). The socio-cultural approach to second language acquisition: Sociocultural theory, second language acquisition, and artificial L2 development. In D. A tkinson (Ed.), Alternative approaches to second language acquisition, (pp. 24-47). London: Routledge.

Larsen-Freeman, D. (1997). Chaos/complexity science and second language acquisition. Applied linguistics, 18(2), 141-165.

Larsen-Freeman, D. (2004). CA for SLA ? It all depends. The Modern Language Journal, 88, 603-607.

Lave, J. (1988). Cognition in Practice. Cambridge: Cambridge U niversity Press.

Lave, J. \& W enger, E. (1991). Situated learning. Legitimate peripheral participation. Cambridge U niversity Press.

Lazaraton, A. (2004). Gesture and speech in the vocabulary explanations of one ESL teacher: A microanalytic inquiry. Language learning, 54(1), 79-117.

LeB aron, C. (1998). Building communication: Architectural gestures and the embodiment of new ideas. U npublished dissertation. U niversity of Texas, A ustin, TX.

LeB aron, C., \& Streeck, J. (2000). Gestures, knowledge, and the world. In D. M cNeill (Ed.), Gestures in action, language, and culture, (pp. 118-138). Cambridge, M A : Cambridge U niversity Press.

Lee, Y. A. ( 2007 ). Third turn position in teacher talk: Contingency and the work of teaching. Journal of Pragmatics, 39 (1), 180-206.

Lehman, W. P. \& Jones, R. L. (1987). The humanistic basis of second language learning. Annals of the American Academy of Political and Social Science, 490, Foreign language instruction: A national agenda, 186-193.

Lehre, R. \& Shauble, L. (2011). D esigning to support long term growth and development. In T. K oschmann, Theories of learning and studies of instructional practice, (pp. 19-38). $\mathrm{N}$ ew Y ork: Springer.

Lerner, G. H. (1995). Turn design and the organization of participation in instructional activities. Discourse Processes, 19 (1), 111-131.

Lerner , G. H. ( 1996). On the ' semi - permeable' character of grammatical units in conversation: Conditional entry into the turn space of another speaker. In E. O chs, E. A. 
Schegloff \& S. A. Thompson (Eds.), Interaction and grammar, (pp. 238 - 276). Cambridge : Cambridge U niversity Press .

Lerner , G. H. ( 2002 ). Turn - sharing: The choral co-production of talk -in- interaction. In C. Ford , B. A. Fox \& S. A. Thompson (Eds.), The language of turn and sequence, (pp. 225 - 256 ). Oxford: Oxford U niversity Press.

L evinson, S. (1983). Pragmatics. Cambridge: Cambridge University Press.

Levinson, S. (1992). Activity types and language. In P. Drew \& J. Heritage (Eds.). Talk at work, (pp. 66-100). Cambridge: Cambridge U niversity Press.

Levinson, S. (2013). A ction formation and ascription. In J. Sidnell \& T. Stivers (Eds.). The handbook of conversation analysis, (pp. 103-130). Malden MA and Oxford: WileyBlackwell.

Lindberg, I. (1995). Second language discourse in and out of classrooms. Studies of learner discourse in the acquisition of Swedish as a second language in educational contexts. PhD. Diss., Centre for Research on Bilingualism, Stockholm U niversity.

Lindberg, I. (2003). Second language awareness: What for and for whom? Language Awareness, 12(3-4), 157-171.

Lindberg I. \& Sandwall, K. (2007). Nobody's darling? Swedish for adult immigrants: A critical perspective. Prospect, 22(3), 79-95.

Lindberg, I. \& Skeppstedt, I. (2000) Ju mer vi lär tillsammans - rekonstruktion av text i smågrupper. In H. Åhl (Ed.), Svenska i Tiden-Verklighet och Visioner. Stockholm: $\mathrm{N}$ ationellt centrum, HLS förlag.

Lindwall, 0.\& Ekström, A . (2012). Instruction-in-interaction: The teaching and learning of a manual skill. Human Studies, 35, 27-49.

Lindwall, 0.\& Lymer, G. (2008). The dark matter of lab work: Illuminating the negotiation of disciplined perception in mechanics. Journal of the Learning Sciences, 17(2), 180224.

Linell, P. (1998). Approaching dialogue. A msterdam: J ohn B enjamins.

Linell, P. (2009). Rethinking language, mind and world dialogically - interactional and contextual theories of human sense-making. Charlotte, NC: Information Age Publishing Inc.

Linell, P. (2014). Interactivities, intersubjectivities, and language: On dialogism and phenomenology. To appear in Language and Dialogue.

Long, M. H. (1981). Input, interaction, and second language acquisition. Annals of the New York Academy of Sciences, 379, 259-278. 
Long, M. H. (1996). The role of the linguistic environment in second language acquisition. In W. C. Ritchie \& T. K. Bhatia (Eds.), Handbook of second language acquisition, (pp. 413-468). San Diego: Academic Press.

Luff, P. \& Heath, C. (2012). Some 'technical challenges' of video analysis: Social actions, objects, material realities and the problems of perspectives. Qualitative Research, 12(3), 255-279.

Luff, P., Heath, C. \& Pitsch, K. (2011). Indefinite precision: The use of artefacts-ininteraction in design word. In C. J ewitt (Ed.), The Routledge handbook of multimodal analysis, (pp. 213-222). London: Routledge.

Lymer, G., Ivarsson J. \& Lindwall, 0. (2009). Contrasting the use of tools for presentation and critique: Some cases from architectural education. Computer-Supported Collaborative Learning, 4, 423-444.

Lynch, M. (1985). Art and artifact in laboratory science: A study of shop work and shop talk in a research laboratory. London: R outledge.

M acbeth, D. (1990). Classroom order as practical action: The marking an un-marking of a quiet reproach. British Journal of Sociological Education, 11(2), 189-214.

M acbeth, D. (2003). Hugh Mehan's Learning Lessons reconsidered: On the differences between the naturalistic and critical analysis of classroom discourse. American Educational Research Journal, 40(1), 239-280.

M acbeth, D. (2004). The relevance of repair for classroom correction. Language in Society, 33, 703-736.

M acbeth, D. (2011). Understanding understanding as an instructional matter. Journal of Pragmatics, 43, 438-451.

M acbeth, D. (2014) "Studies of work, instructed action, and the promise of granularity": A commentary. To appear in Discourse Studies

MacW hinney, B. (1998). Models of the emergence of language. Annual Review of Psychology, 49, 199-227.

M acW hinney, B. (2005). The emergence of linguistic forms in time. Connection Science, 17(3-4), 191-211.

M ajlesi, A. R. \& Broth, M. (2012). Emergent learnables in second language classroom interaction. Learning, Culture and Social Interaction, 1, 193-207.

Majlesi, A. R. (2014). Finger dialogue. The embodied accomplishment of learnables in instructing grammar on a worksheet. To appear in Journal of pragmatics.

M arkee, N. (2000). Conversation analysis. M ahwah, N J: Erlbaum.

M arkee, N. (2004). Classroom talks [Special issue]. The Modern Language Journal, 88(4). 
M arkee, N. (2008). Towards a learning behavior tracking methodology for CA-for SLA. Applied Linguistics, 29, 404-427.

M arkee, N. (2011). Doing, and justifying doing avoidance. Journal of Pragmatics, 43, 602615.

M arkee, N . \& K asper, G. (2004). Classroom talks: A n introduction. The Modern Language Journal, 88(4), Special issue: Classroom talks, 491-500.

M aynard, D. W . (2006). Cognition on the ground. Discourse Studies, 8(1), 105-115.

M cCafferty, S. G. (2002). Gesture and creating zone of proximal development for second language learning. The Modern Language Journal, 68(2), 192-203.

M cHoul, A. W. (1978). The organization of turns at formal talk in the classroom. Language in Society, 7(2), 183-213.

M cHoul, A. W . (1990). The organization of repair in classroom talk. Language in Society, 19(3), 349-377.

MCNeill, D. (1992). Hand \& Mind: what Gestures Reveal about Thought. Chicago: U niversity of Chicago Press.

M ead, G. H. (1910). Social consciousness and the consciousness of meaning. Psychological Bulletin, 7, 397-405.

Mehan, H. (1979). Learning Lessons: Social organization in the classroom. Cambridge: M ass.: Harvard University Press.

Melander, H. (2012). Transformation of knowledge within a peer group. Knowing and learning in interaction. Learning, Culture and Social Interaction, 1, 232-248.

M elander, H.\& Sahltsröm, F. (2009). In tow of the blue whale. Learning as interactional changes in topical orientation. Journal of Pragmatics, 41, 1519-1537.

M ilton, J. (2009). Measuring second language vocabulary acquisition. B ristol: M ultilingual $M$ atters.

Moerman, M. \& Sacks, H. (1988). On 'understanding' in the analysis of natural conversation. In M. Moerman (Ed.), Talking culture, (pp. 180-186). Philadelphia: University of Pennsylvania Press. (Original work published 1971)

M ogk, D.W . \& Goodwin, C. (2012). Learning in the field: Synthesis of research on thinking and learning in the geosciences. In K. A. K astens \& C. A. M anduca (Eds.), Earth and Mind II: A Synthesis of Research on Thinking and Learning in the Geosciences: Geological Society of America Special Paper 486, (pp. 131-163).

M ondada, L. (2006). V ideo recordings as the reflective preservation and configuration of phenomenal features for analysis. In H. Knoblauch, H-G. Soeffner, J. Raab \& B. Schnettler (Eds.), Video analysis, (pp.51-68). B ern: Lang. 
M ondada, L. (2007a). Multimodal resources for turn-taking: pointing and emergence of possible next speakers. Discourse Studies, 9(2), 194-225.

M ondada, L. (2007b). Comment: transcript variations and the indexicality of transcribing practices. Discourse Studies, 9/6, 809-821.

M ondada, L. (2010). Understanding as an embodied, situated and sequential achievement in interaction. Journal of Pragmatics, 43, 542-552.

M ondada, L. (2013). The conversation analytic approach to data collection. In J. Sidnell \& T. Stivers (Eds.), The handbook of conversation analysis. (pp. 32-56) Malden, M A and Oxford: W iley-B lackwell.

Mondada, L. \& Pekarek Doehler, S. (2004). Second language acquisition as situated practice: task accomplishment in the French second language classroom. The Modern Language Journal, 88(4), 501-18.

M ori, J. (2002). Task design, plan, and development of talk-in-interaction: An analysis of a small group activity in a J apanese language classroom. Applied Linguistics, 23, 323347.

Mori, J. \& Hayashi, M. (2006). The achievement of intersubjectivity through embodied completions: a study of interaction between first and second language speakers. Applied Linguistics, 27(2), 195-219.

M ori J. \& M arkee, N. (2009). Language learning, cognition, and interactional practices: A $n$ introduction. IRAL, 47, 1-9.

M ortensen, K. (2011). Doing word explanation in interaction. In G. Pallotti \& Wagner, J. (Eds.), L2 learning as social practice: Conversation analytic perspectives, (pp. 135162). Honolulu, Hawaii: National Foreign Language Resource Center, University of Hawaii at mānoa.

M urphy, K. M . (2004). Imagination as a joint activity: The case of architectural interaction. Mind, Culture and Activity, 11(4), 267-278.

M urphy, K. M . (2005). Collaborative imagining: The interactive use of gestures, talk, and graphic representation in architectural practice. Semiotica, 156(1/4), 113-145.

Murphy, K. M. (2012). Transmodality and temporality in design interactions. Journal of Pragmatics, 44, 1966-1981.

M usk, N. (2013). A voiding the target language with the help of G oogle: M anaging language choices in gathering information for EFL project work. To appear in TESOL Quarterly.

Nishizaka, A . (2006). W hat to learn: The embodied structure of the environment. Research on Language and Social Interaction, 39(2), 119-154. 
Norman, K. (2004). Equality and exclusion: 'Racism' in a Swedish town. Ethnos, 69(2), 204-228.

N orberg, K. (2000). Intercultural education and teacher education in Sweden. Teaching and Teacher Education, 16, 511-519.

Ochs, E. (1982). Talking to children in western Samoa. Language in Society, 11(1), 77-104.

Ochs, E. \& Schieffelin, B. B. (1979). Developmental pragmatics. New Y ork: Academic Press.

Ohta, A. S. (2000). Rethinking interaction in SLA: developmentally appropriate assistance in the zone of proximal development and the acquisition of L 2 grammar. In J. Lantolf (Ed.), Sociocultural theory and second language learning, (pp. 51-78). Oxford: Oxford U niversity Press.

Olsher, D. (2004). Talk and gesture: the embodied completion of sequential actions in spoken interaction. In R. Gardner \& J. W agner (Eds.), Second language conversations, (pp. 221-245). London: Continuum.

Opper, S. (1983). Multiculturalism in Sweden: A case of assimilation and integration. Comparative Education, 19(2), 193-212.

Ortega, L. (2011). SLA after the social turn. Where cognitivism and its alternatives stand. In A tkinson, D. (2011). Alternative approaches to second language acquisition, (pp. 167180). London: Routledge.

Pekarek-D oehler, S. (2002). M ediation revisited: the interactive organization of mediation in learning environments. Mind, Culture, and Activity, 9(1), 22-42.

Peräkylä, A. (2006) Observation and video analysis. In P. Drew, G. Raymond \& D. W einberg (E ds.), Talk in Interaction in Social Research Methods, (pp. 81-96). London: Sage.

Piaget, J. (1926). The language and thought of the child. N ew Y ork: H arcourt B race \& Co.

Piaget, J. (1952). The origins of intelligence in children. N ew Y ork: International U niversity Press. (O riginal work published 1936).

Piaget, J. (1961). The genetic approach to the psychology of thought. Journal of Educational Psychology, 52(6), 275-281.

Piaget, J. (1980). The psychogenesis of knowledge and its epistemological significance. In: M. Piattelli-Palmarini (Ed.), Language and learning: the debate between Jean Piaget and Noam Chomsky. Cambridge, M ass.: H arvard University Press.

Piattelli-Palmarini, M. (1980). Language and learning: the debate between Jean Piaget and Noam Chomsky. Cambridge, M ass.: Harvard University Press. 
Pica, T., Y oung, R. \& Doughty, C. (1987). The impact of interaction in comprehension. TESOL Quarterly, 21(4), 737-758.

Pike, K. L. (1954). Language in relation to a unified theory of the structure of human behavior. Glendale, CA : Summer Institutes of Linguistics.

Plejert, C. (2004) To Fix What's Not Broken. Repair Strategies in Non-Native and Native English Conversation. PhD. Diss., Linköping: L inköping U niversity Electronic Press.

Plejert, C., Jansson, G. \& Y azdanpanah, M. (2014). Response practices in multilingual interaction with an older Persian woman in a Swedish residential home. Journal of Cross-Cultural Gerontology, 29, 1-23.

Pomerantz, A. (1984). A greeing and disagreeing with assessments: Some features of preferred/dispreferred turn shapes. In J. M. A tkinson \& J. Heritage (Eds.), Structures of Social Action, (pp. 57-101). Cambridge: Cambridge U niversity Press.

Potter, J. (2006). Cognition and conversation. Discourse Studies, 8(1), 131-140.

Psathas, G. (1979). Everyday language - Studies in ethnomethodology, (pp. 123-162). N ew Y ork: Irvington Publishers.

Radford, L. (2003). Gestures, speech, and the sprouting of signs: semiotic-cultural approach to students' types of generalization. Mathematical thinking and learning, 5(1), 37-70

Radford L., Demers, S., Guzmán, J. \& Cerulli, M . (2003). Calculators, graphs, gestures and the production of meaning. In N. Pateman, B. Dougherty \& J. Zilliox (Eds.), Proceedings of the 27 conference of the international group for the psychology of mathematics education (PM E27-PM ENA 25), V ol. 4, 55-62.

Rawls, A. W. (2002). Introduction. In H. Garfinkel, Ethnomethodology's program. Working out Durkheim's aphorism, (pp. 1-64), A. W. Rawls (Ed.). Lanham, M aryland: Rowman $\&$ Littlefield Publishers.

Rosén, J. K . \& Bagga-Gupta, S. (2013). Shifting identity positions in the development of language education for immigrants: An analysis of discourses associated with 'Swedish for immigrants'. Language, Culture and Curriculum, 26(1), 68-88.

Sacks, H. (1963). Sociological description. Berkley Journal of Sociology, 8(1), 1-16.

Sacks, H. (1974). A n analysis of the course of a joke's telling in conversation. In J. Sherzer, R. Bauman, (Eds.), Explorations in the ethnography of speaking, (pp. 337-353). Cambridge: Cambridge U niversity Press.

Sacks, H. (1984a). Notes on methodology. In M. J. Atkinson \& J. Heritage (Eds.), Structures of social action: Studies in conversation analysis, (pp. 21-27). Cambridge: Cambridge University Press.

Sacks, H. (1992a,b). Lectures on conversation, V ol. 1 \& 2. Oxford: Blackwell. 
Sacks, H., Schegloff, E. A. \& Jefferson, G. (1974). A simplest systematics for the organization of turn taking for conversation, Language, 50, 696-735.

Sahlström, F. (1999). Up to the hill backwards: On interactional constraints and affordances for equity-constitution in the classrooms of the Swedish comprehensive school. PhD. Diss. U ppsala: A cta U niversitatis U psaliensis.

Schegloff, E. A . (1968). Sequencing in conversational openings. American Anthropologist, 70(6), 1075-1095.

Schegloff, E. A. (1979). The relevance of repair to syntax-for- conversation. In T. Givón (Ed.), Syntax and Semantics: Discourse and syntax, V ol. 12, (pp. 261-286). N ew Y ork: A cademic Press.

Schegloff, E. A . (1984). On some gestures' relation to talk. In. J. M. A tkinson \& J. Heritage (Eds.), Structures of social action. Studies in conversation analysis, (266-296). Cambridge: Cambridge U niversity Press.

Schegloff, E. A . (1987). B etween micro and macro: Contexts and other connections. In J. C. A lexander, B. Giesen, R, M ünch \& N. J. Smelser, The micro macro link, (pp. 207-234). Berkeley: University of California Press.

Schegloff, E. A. (1988). Goffman and the analysis of conversation. In P. Drew \& A. Wootton, (Eds.), Erving Goffman. Exploring the interaction order, (pp. 89-135). Cambridge: Polity Press.

Schegloff, E. A. (1991). Conversation analysis and socially shared cognition. In L. B. Resnick, J. M. L evine \& S. D. Teasley (Eds.), Perspectives on socially shared cognition, (pp. 150-171). Washington: A merican Psychological A ssociation.

Schegloff, E. A . (2007). Sequence Organization in Interaction: A Primer in Conversation Analysis, V ol. 1. Cambridge: Cambridge University Press.

Schegloff, E. A . \& Sacks, H. (1973). O pening up closing. Semiotica, 8(4), 289-327.

Schegloff, E. A., J efferson, G. \& Sacks, H. (1977). The preference for self-correction in the organization of repair in conversation, Language, 53, 361-82.

Schieffelin, B. B. \& Ochs, E. (1986). Language socialization across cultures. Cambridge: Cambridge U niversity Press.

Schutz, A. (1967). The phenomenology of the social world. Evanston and Chicago: N orthwestern U niversity Press. (O riginal work published 1932).

Schutz, A. (1975). Collected papers III. Studies in phenomenological philosophy, I. Schutz (Ed.). The Hague: M artinus Nijhoff.

Seedhouse, P. (1998). CA and the analysis of foreign language interaction: A reply to W agner. Journal of Pragmatics. 30, 85-102. 
Seedhouse, P. (2004). The Interactional Architecture of the Language Classroom: A Conversation Analysis Perspective. M alden, M A : B lackwell.

Seedhouse, P. (2005). Conversation analysis and language learning. Language Teaching, 38, 165-187.

Seedhouse, P. (2007). On ethnomethodological CA and "linguistic CA": A reply to Hall, The Modern Language Journal, 91(4), 526-532.

Seedhouse, P., Walsh, S. \& Jenks, C. (2010). Conceptualizing 'learning' in applied linguistics. Hampshire and $\mathrm{N}$ ew $\mathrm{Y}$ ork: Palgrave Macmillan.

Selinker, L. (1972). Interlanguage. IRAL, 10(1-4), 209-232.

Seo, M. (2011). Talk, body, and material objects as coordinated interactional resources in repair activities in one-on-one ESL tutoring. In G. Pallotti \& J. Wagner (Eds.), L2 learning as social practice - conversation-analytic perspective, ( $\mathrm{pp}$. 107-134). Honolulu, Hawaii: National Foreign Language Resource Centre, University of Hawaii at Mānoa.

Sfard, A. (1998). On two metaphors for learning and the dangers of choosing just one. Educational Researcher, 27(2), 4-13.

Sidnell, J. (2006). Coordinating gesture, talk, and gaze in reenactments. Research on Language and Social Interaction, 39(4), 377-409.

Sinclair, J. M . \& Coulthard, M . (1975). Towards an analysis of discourse. London: Oxford University Press.

Singer, M. A . \& Goldin-M eadow, S. (2005). Children learn when their teacher's gestures and speech differ. Psychological Science, 16, 85-89.

Skinner, B. F. (1957). Verbal behavior. New Y ork: A ppleton-Century-Crofts.

Skinner, B. F. (1985). Cognitive science and behaviourism. British Journal of Psychology, 76, 291-301.

Skolinspektions rapport [School inspection report], (2011). Ändamålsenlighet och resultat $i$ svenskundervisning för invandrare [Efficiency and result in Swedish teaching for immigrants], (Kvalitetsgranskning, Rapport 2011:6). Stockholm: Diarienummer 402010:575.

Skolverket (2012). Utbildning $i$ Svenska för invandrare. Kursplan och Kommentarer [Education in Swedish for immigrants. Syllabus and comments]. V ästrås: Edita.

Slotte-Lüttge, A . (2005). Ja vet int va de heter på svenska: Interaktion mellan tvåspråkiga elever och deras lärare i en enspråkig klassrumsdiskurs [I don't know what it is called in Swedish: Interaction between bilingual students and their teacher in a monolingual classroom discourse]. PhD. Diss., Å bo: Å bo A kademis förlag. 
Stivers, T. \& Robinson, J. D. (2006). A preference for progressivity in interaction. Language in Society, 35, 367-392.

Stivers, T. \& Sidnell, J. (2005). Introduction: M ultimodal interaction. Semiotica, 156(1/4), $1-20$.

Streeck, J. (1996). How to do things with things. Human Studies, 19(4), 365-384.

Streeck, J. (2008). Gesture in political communication: A case study of democratic presidential candidates during the 2004 primary campaign. Research on Language and Social Interaction, 41(2): 154-186.

Streeck, J. (2009). Depicting gestures. Examples of the analysis of embodied communication in the arts of the West. Gesture, 9(1), 1-34.

Streeck, J. (2013). Interaction and the living body. Journal of Pragmatics, 46, 69-90.

Streeck, J. \& Jordan, J. S. (2009). Communication as a dynamic self-sustaining system: The importance of time-scales and nested context. Communication Theory, 19, 445-464.

Streeck, J., Goodwin, C. \& LeBaron C. (2011), Embodied interaction. Language and body in the material world. Cambridge: Cambridge University Press.

Svinhufvud, K. \& Vehviläinen, S. (2013). Papers, documents, and the opening of an academic supervision encounter. Text and Talk, 33(1), 139-166.

Szczepek Reed, B., Reed, D. \& Haddon, E. (2013). NOW or NOT NOW: Coordinating restarts in the pursuit of learnables in vocal master classes. Research on Language and Social Interaction, 46(1), 22-46.

Swain, M. (1985). Communicative competence: some roles of comprehensible input and comprehensible output in its development. In S. Gass \& C. Madden (Eds.), Input in second language acquisition, (pp. 235-253). Rowley, M A : N ewbury House.

Swain, M., K innear, P. Steinman, L. (2011). Sociocultural theory in second language learning. An introduction through narratives. Kindle Edition. B ristol: Multilingual $M$ atters.

Swain, M . \& Lapkin, S. (1998). Canadian immersion and adult language teaching: What's the connection? The Modern Language Journal, 73(2), 150-159.

Thorndike, E. L. (1931). On the learning of rules in the study of a foreign language. The German Quarterly, 4(3), 89-95.

Tomasello, M. (1998). Introduction: A cognitive-functional perspective on language structure. In M. Tomasello (Ed.), The new psychology of language. Cognitive and functional approaches to language structure. M ahwah, $\mathrm{N}$ ew J ersey: Lawrence Erlbaum.

Tomasello, M. (2003). Constructing a language. A usage-based theory of language acquisition. Cambridge, M A : Harvard U niversity Press. 
Tomasello, M. (2008). Origins of human communication. Cambridge, M ass.: The M IT Press.

Tomasello, M . \& Zuberbühler, K. (2002). Primate vocal and gestural communication. The cognitive animal: empirical and theoretical perspectives on animal cognition, (pp. 29329). Cambridge, M ass.: The M IT Press.

van Lier, L. (1988). The classroom and the language learner: Ethnography and second language classroom research. London and $\mathrm{New}$ Y ork: Longman.

V arela, F. J., Thompson, E. \& Rosch, E. (1991). The embodied mind: Cognitive science and human experience. Cambridge, M ass.: M IT Press.

Varonis, E. M . \& Gass, S. M (1985). M iscommunication in native/nonnative conversation. Language in Society, 14(3), 327-343.

Vygotsky, L. S. (1978). Mind in society. The development of higher psychological processes. Cambridge, M A: Harvard University Press.

Vygotsky, L. S. (1986). Thought and language, A. Kozulin (Ed.). Cambridge, M A: M IT Press.

W alsh, S. (2011). Exploring classroom discourse. Language in action. London: Routledge.

W enger, E. (1998). Communities of practice. Learning, meaning, and identity. Cambridge: Cambridge U niversity Pres.

Weeks, P. (1996). A rehearsal of a Beethoven passage: A $n$ analysis of correction talk. Research on Language and Social Interaction, 29(3), 247-290.

W ittgenstein (2009). Philosophical investigations, G. E. M. A nscombe, P. M. S. Hacker \& J. Schulte, (Trans.). Malden, MA and Oxford: Wiley-Blackwell. (Original work published, 1953).

W undt, W. (1973). The language of gestures. The Hague and Paris: Mouton (original published 1904 as part of Völkerpsychologie series)

Y oung, R. F. \& Miller, E. R. (2004). Learning as changing participation: negotiating discourse roles in the ESL writing conference. Modern Language Journal, 88, 519-535.

Zemel, A . \& K oschmann, T. (2011). Pursuing a question: Reinitiating IRE sequences as a method of instruction. Journal of Pragmatics, 43, 475-488.

Zemel, A . \& Koschmann, T. (2014). Put your fingers in there: Learnability and instructed experience. To appear in Discourse Studies. 


\section{STUDIES 1 - 4}





\section{Studies}

The articles associated with this thesis have been removed for copyright reasons. For more details about these see:

http://urn.kb.se/resolve?urn=urn:nbn:se:liu:diva-104920 